\title{
UNCITRAL Y LAS OSCILACIONES DEL RÉGIMEN JURÍDICO DEL TRANSPORTE MARÍTIMO INTERNACIONAL DE MERCANCÍAS. ADVERTENCIAS EN TORNO A LA BÚSQUEDA DE UNA TERCERA VÍA
}

\section{David ENRÍQUEZ*}

RESUMEN: El presente artículo estudia los dos regímenes de responsabilidad en el transporte marítimo de mercancías, conocidos respectivamente como las Reglas de La Haya-Wisby y las Reglas de Hamburgo. Asimismo, el autor analiza brevemente el proyecto de convenio que es desarrollado sobre el tema por Uncitral. Si bien puede concluirse que el instrumento aporta una mayor eficacia y equidad al sistema, los potenciales abusos a su régimen, a través del posible uso ilegítimo de los contratos de volumen, debe ser objeto de advertencia a la comunidad jurídica.

ABSTRACT: The present article addresses the two liability regimes concerning the transport of goods by sea, known respectively as the Hague-Wisby Rules and the Hamburg Rules. Likewise, the author briefly analyzes the draft convention on the subject, which is being developed by Uncitral. Although it may be concluded, that the instrument offers greater effectiveness and fairness to the system, the potential abuses to the regimen through the illegitimate handling of the volume contracts shall be a warning to the legal community.

RÉSUMÉ: L'article étudie les deux régimes de responsabilité dans le transport maritime de marchandises connue respectivement comme les Règles de la Haye-Wisby et les Règles de Hambourg. De la même forme, l'auteur analyse brièvement le projet d'accord qui est développe sur le sujet par Uncitral. Même si on peux conclure que l'instrument apport un majeur efficacité et équité au système, les potentiels abus a son régime, au travers de l'usage illégitime des contrats de volume doit être objet d'avertissement à la communauté juridique.

* Doctor en derecho e investigador nacional nivel 1 (SNI). Las secciones II a IV del presente artículo tienen como base el análisis que el propio autor formula de las RHW y las RHa en sus libros Transporte internacional de mercancias, así como Transportes y seguros para el comercio internacional. 


\begin{abstract}
SUMARIO: I. Aproximación. II. Evolución histórica de la responsabilidad del transportista marítimo de mercancías en las fuentes internacionales. III. Claves en el sistema de responsabilidad del transportista marítimo bajo las Reglas de la Haya-Wisby. IV. Claves en el sistema de responsabilidad del transportista maritimo bajo las Reglas de Hamburgo. V. Uncitral y la búsqueda de una tercera vía. VI. Comentarios conclusivos.
\end{abstract}

\title{
I. APROXIMACIÓN
}

El incremento vertiginoso de la última década en el comercio mundial no podría haber tenido lugar sin el desarrollo de la industria naviera internacional. La complejidad tecnológica e innovación administrativa, acompañadas de sistemas vinculantes más efectivos en la seguridad de la vida humana en el mar, así como la protección ante conductas delictivas y la prevención de la contaminación ambiental han hecho posible que hoy, la industria naval lleve a cabo más del $90 \%$ del transporte mundial y contribuya con un $5 \%$ de la economía del planeta. ${ }^{1}$

Más de 10,000 empresas navieras están encargadas de la operación eficiente de aproximadamente 50,000 embarcaciones de 150 países, dedicadas a tráficos internacionales, gracias a la habilidad y el entusiasmo de un millón de marinos. Este intrincado cúmulo de esfuerzos del sector privado, de organismos internacionales y de jurisdicciones nacionales hace posible que el transporte marítimo continúe siendo el modo de transporte más competitivo en términos de costos.

Por ejemplo, el costo de transportar un contenedor de 20 pies, de Asia a Europa, con 20 toneladas de carga dentro, es casi el mismo que un boleto de avión para el mismo trayecto. El costo para un consumidor de Estados Unidos de América (EUA) de transportar petróleo crudo desde el Medio Oriente, en términos del precio final del combustible en la estación gasolinera de la esquina de su casa, es de menos de un centavo de dólar por litro. O el costo de transportar por mar una aspiradora de China a México probablemente no rebasará los 12 pesos mexicanos. ${ }^{2}$

1 Véase UNCTAD, Review of Maritime Transport, 2004, Ginebra, 2004, pp. X y ss.

2 Véase ICS et al., International Shipping. Carrier of World Trade, 2006. Véase, asimismo, de este grupo de cámaras internacionales: www.shippingfacts.com. 
Aunque son distintos los organismos internacionales involucrados total o parcialmente en la regulación de la industria marítima - OMI, FIDAC, IMSO, OIT, etcétera-, el propósito de este artículo es centrarse en la reciente labor de uno de ellos: Uncitral (la Comisión de las Naciones Unidas para el Derecho Mercantil Internacional; CNUDMI en castellano). Esta pequeña - pero influyente - institución del Sistema de las Naciones Unidas tiene la grave misión de actualizar el sistema de responsabilidad del transportista a la realidad de los tráficos del siglo XXI.

Sería todavía aventurado afirmar que el loable trabajo de delegados nacionales y secretariado de Uncitral arribará a puerto seguro en el futuro próximo. Sin embargo, sí parece un momento oportuno para hacer un breve alto en el camino y valorar algunos elementos claves, tanto de los sistemas de responsabilidad sujetos a revisión — RHW y Rha-, como del proyecto de Uncitral.

La navegación, como todo acto efectuado por una persona, implica necesariamente la asunción de una cierta responsabilidad para quien la desarrolle; como en cualquier otra materia, la gama de esta responsabilidad se concreta según la fuente de la obligación. Así, surge por un lado, la responsabilidad contractual de acuerdo a lo que cargador y transportista hayan convenido de conformidad con la lex contractu y el respeto a las normas imperativas del ordenamiento legislativo aplicable. Por otro lado, surge también la responsabilidad extracontractual o aquiliana del porteador en función de los daños que produzca a terceros con quienes no tenga un vínculo contractual. ${ }^{3}$

En este artículo nos enfocaremos a los elementos que se derivan del primer género de responsabilidad en el ámbito del derecho privado. De su exposición podremos advertir que el derecho marítimo pone de relieve uno de sus claros y tradicionales particularismos al separarse de los pos-

3 Véase, además, Ennecerus, Ludwig, Derecho de las obligaciones, Barcelona, Bosch, 1966, pp. 1021 y ss.; Tunc, André, La responsabilité civile, París, Económica, 1981, pp. 133 y ss.; Ferrari, Luigi, Responsabilitá civile e Diritto internazionale privato, Napoles, 1973, pp. 82 y ss.; Diez-Picazo, Luis, Fundamentos del derecho civil patrimonial, Madrid, Civitas, 1993, vol. II, pp. 573 y ss.; Maiorca, Carlo, I fondamenti della responsabilitá, Milán, Giuffré, 1990, pp. 209 y ss.; Bejarano, Manuel, Obligaciones civiles, México, Harla, 1993; Paolo, Guillermo, Aspectos internacionales de la responsabilidad civil por servicios, Granada, Comares, 1995; Messina, Graciela, La responsabilidad civil en la era de la tecnología, Buenos Aires, Abeledo-Perrot, 1989, pp. 19 y ss.; Rogers, W., Winfield and Jolowics on Tort, Londres, Sweet \& Maxwell, 1984, pp. 12 y ss. 
tulados generales del derecho privado e incluso, dentro de él, de los sistemas de responsabilidad contractual del resto de los modos de transporte. ${ }^{4}$

Con el propósito de ofrecer una visión global - aunque elementaldel tema, expondremos a grandes líneas el complejo proceso de la evolución histórica del sistema de distribución del riesgo entre el porteador y el cargador en el seno al transporte marítimo internacional de mercancías. ${ }^{5}$ De ahí concluiremos las diferencias entre el subsistema que aligera la responsabilidad del transportista - RHW-, y aquél que la agrava en beneficio del cargador (y consecuentemente, del consignatario), es decir las llamadas - Rha - ${ }^{6}$ En un segundo momento, tendremos en cuenta las claves específicas de los dos sistemas de responsabilidad, para de ahí valorar la actividad de Uncitral respecto a un posible instrumento internacional que logre conciliar las posiciones - casi- antagónicas de los dos sistemas existentes, y de las ligeras variantes de cada uno de ellos.

4 Es importante tener presente, desde ahora, que el régimen tradicional de responsabilidad del porteador, de acuerdo a la Convención de Bruselas de 1924 y en general a las RHW, es radicalmente distinto al del resto de los instrumentos que regulan el transporte internacional de mercancías, incluyendo al de las RHa que es el instrumento que busca sustituir el tradicional sistema de aquel ordenamiento.

5 Siguiendo a lord Diplock, el profesor Arroyo Martínez esboza el conjunto de relaciones que tienen como escenario el mar y como peligro común el daño, distinguiendo la siguiente clasificación de sujetos primarios y directamente perjudicados en: a) Porteadores y propietarios de la carga que sean parte de la misma relación: rubro que da origen a la distribución del riesgo en el contrato de fletamento, en el contrato de transporte y en la avería común. La expresión propietario de la carga debe ser interpretada en un sentido amplio, comprendiendo con ello al cargador, destinatario, receptor y fletador; siendo todos ellos considerados como una sola parte frente al porteador. b) Personas que se benefician del tráfico marítimo y se encuentran ligadas por una responsabilidad extracontractual: en este apartado encontramos a los terceros navieros cuyos buques sufren accidentes de abordajes; c) Personas extrañas por completo a la aventura maritima: en esta tercera especie tenemos a las víctimas de la contaminación y los daños a terceros en la superficie. De entre las tres categorías de relaciones, nosotros únicamente nos referiremos a la primera de ellas; es decir, al vínculo contractual entre porteador y cargador. Véase Arroyo, Ignacio, Estudios de derecho marítimo, Barcelona, Bosch, 1993, pp. 235 y ss.

6 Mientras que, en la actualidad, México forma parte del sistema de las RHW por haber ratificado dicho instrumento (véase $D O F$ del 25 de agosto de 1994); debe tenerse presente que las RHa se encuentran también en vigor internacional, y que nuestro país es uno de sus estados firmantes; sin embargo, por diversas razones no han sido ratificadas, acto que requeriría la denuncia de las primeras por su mutua exclusión. 


\section{EVOLUCIÓN HISTÓRICA DE LA RESPONSABILIDAD \\ DEL TRANSPORTISTA MARÍTIMO DE MERCANCÍAS EN LAS FUENTES \\ INTERNACIONALES}

\section{Antecedentes de la regulación internacional}

En el derecho romano, el capitán respondía de la custodia de cuanto le había sido confiado para el transporte. Así, no se concebía una responsabilidad por incumplimiento específicamente, ya que todo lo que le era confiado debía ser igualmente restituido (deber de custodia). Como explica el profesor Antonio Brunetti, la responsabilidad era excluida solamente con la presencia de la fuerza mayor y de la culpa del propietario de la cosa. ${ }^{7}$

En este sentido, por edicto pretoriano y mediante una acción civil, la llamada actio receptitia, se responsabilizaba al nauta en forma similar que a los hoteleros y mesoneros. El fundamento de la responsabilidad para todos se encontraba en el citado receptum de las mercancías, con lo que además se introdujo al supuesto, la categoría de responsabilidad por culpa, salvo que las pérdidas hubieran sido causadas por fuerza mayor. ${ }^{8}$

A lo largo de la Edad Media, las fuentes del derecho estatutario - siguiendo al profesor Blas Simone- establecían la responsabilidad del patronus por la custodia de la carga y por la restitución en destino, salvo el caso de la fuerza mayor. Tal responsabilidad derivaba de la presunción de culpa asignada al patrono o al vicio del buque. ${ }^{9}$

Siglos más tarde, las Ordenanzas de Colbert de 1681 recogieron, en lo general, el criterio de las fuentes estatutarias, para que después el influyente Código de Comercio francés de 1807 concretara la normatividad y responsabilizara al porteador de los daños sufridos por las mercancías

7 Así pues, en el derecho romano - concluye el autor- el transportista es responsable de todos los accidentes que habrían podido evitarse con una especial vigilancia. Véase Brunneti, Antonio, Diritto marittimo privato italiano, trad. de Gay de Montellá, Turín, 1950, t. III-a, pp. 269 y ss.; Blas, Osvaldo, Compendio de derecho de la navegación, Buenos Aires, Depalma, 1987, pp. 331 y ss.; Diez, Alberto, Derecho de la navegación, Buenos Aires, Librería Editorial Macchi Hnos., 1954, t. II, pp. 292 y ss.; Vigier, Agustín, Derecho marítimo, Madrid, Subsecretaría de la Marina Mercante, Inspección General de Enseñanza Marítima y Escuelas, 1977, pp. 608 y ss.

8 Idem.

9 Blas, Osvaldo, op. cit., nota 7, pp. 333 y ss. Véase entre las fuentes estatutarias que siguieron este criterio: Consulado del Mar, Roles D’Oléron, Jugements de Dame, Wisby. 
transportadas, salvo que los daños se hubieren derivado del caso fortuito o la fuerza mayor, el vicio de la mercancía o la culpa del cargador. ${ }^{10}$

Como reacción al rígido sistema tradicional basado en la responsabilidad ex recepto, los porteadores marítimos, bajo la tolerancia de los órganos de gobierno de sus países, se volcaron - sobre todo a partir del siglo XIX - a la práctica de insertar cláusulas de irresponsabilidad en los conocimientos de embarque expedidos, hasta llegar al extremo de estipular genéricamente su irresponsabilidad en los casos de hechazón, baratería, daños, errores y cualquier otro acto negligente o faltas de capitán, piloto o tripulación en la administración o en la conducción del buque. ${ }^{11}$ Esto llevó a la supremacía de la nueva responsabilidad ex scriptura en oposición a la antigua responsabilidad derivada del receptum. ${ }^{12}$

El abuso del contenido de la cláusula de irresponsabilidad (negligence clause), la expansión de su utilización, la contradicción de fallos que sostenían la validez o la invalidez de las mismas, y sobre todo la posición de EUA como país mayoritariamente cargador, propició la elaboración y aprobación en 1893 de una ley federal estadounidense denominada como la Harter Act, en honor al senador Michel D. Hart, jefe de su comisión proyectista. ${ }^{13}$

Por este ordenamiento, explica el profesor Domingo Ray, se declararon ilegales las cláusulas que tenían por fin exonerar al transportista de la debida diligencia para armar, equipar y aprovisionar el buque; esto es, para ponerlo en estado de navegabilidad, así como todas aquellas que exoneraran por faltas cometidas al efectuar la carga, la estiba, el cuidado durante el viaje y durante la descarga de la mercancía. Por otra parte, se

10 Véase Ripert, Georges, Compendio de derecho marítimo, trad. de Pedro San Martín, Buenos Aires, Tipográfica Editora Argentina, 1954, pp. 255 y ss.; Rodiere, René, Droit maritime, París, Précis Dalloz, 1991, pp. 249 y ss.; Vialard, Antoine, Droit maritime, París, Presses Universitaires de France, 1997, pp. 405 y ss.; Maraist, Frank, Admiralty, Baton Rouge, West Publishing Co., 1988, pp. 59 y ss.; Gilmore, Grant \& Black, Charles, The Law of Admiralty, Nueva York, Foundation Press Inc., 1975, pp. 180 y ss.; Longley, Henry, Common carriage of cargo, Nueva York, Editorial Matthew Bender, 1967, pp. 12 y ss.

11 Cfr. con Healy \& Sharpe, op. cit., pp. 330 y ss.; Gilmore \& Black, op. cit., nota anterior, pp. 180 y ss.; Maraist, Frank, op. cit., nota anterior, pp. 59 y ss.; Scrutton, T., op. cit., pp. 225 y ss.; Longley, Henry; op. cit., nota anterior, pp. 12 y ss.

12 Blas, Osvaldo, op. cit., nota 7, p. 335.

13 Véase Gilmore \& Black, op. cit., nota 10, pp. 180 y ss.; Healy \& Sharpe, op. cit., nota 11, pp. 330 y ss.; Maraist, Frank, op. cit., nota 10, pp. 59 y ss. 
admitió expresamente la irresponsabilidad del porteador por las faltas cometidas por el capitán en la navegación y manejo (management) del buque y la limitación de su responsabilidad. ${ }^{14}$

De esta manera, la ley Harter no sólo favoreció la eliminación de la práctica internacional de inserción de cláusulas de irresponsabilidad en los conocimientos de embarque, sino que elaboró además todo un sistema por el que distribuía los riesgos derivados de la aventura marítima, centrándose en el deber del porteador de poner la embarcación en estado de navegabilidad al inicio de la travesía y regulando su responsabilidad en el manejo de la carga. ${ }^{15}$ La repercusión internacional de la Harter Act no tomó mucho tiempo, con lo que a menos de tres décadas del inicio de su vigor, ya los ordenamientos de transporte marítimo internacional habrían de tomarla como punto de partida para su desarrollo. ${ }^{16}$

\section{Aproximación al sistema de las llamadas Reglas de La Haya-Wisby:} de las Reglas de La Haya de 1921 a la Convención de Bruselas de 1924 y sus protocolos modificatorios de 1968 y 197917

La influencia de la ley Harter más allá de sus fronteras pudo ya observarse de modo importante a inicios de los años veinte, con la iniciati-

14 Ray, Domingo, op. cit., t. II, p. 384.

15 Como bien sintetiza Frank Maraist: "The basic allocation of risks in the Harter Act is that the carrier must use due deligence to send out a seaworthy vessel at the commencement of the voyage, and is responsible for negligence in the handling of the cargo during the voyage. If he uses due diligence to send out a seaworthy vessel, the carrier is not responsible for damage caused by other designated risks, such as error in navigation or management of the vessel and insufficiency of packaging, and he may by contract (clauses in the bill of lading) exculpate himself from other risks except negligence in handling the cargo". Véase Maraist, Frank, op. cit., nota 10, p. 59.

16 A nivel internacional esto ocurrió a partir de la aprobación de las Reglas de La Haya de 1921 y de la Convención de Bruselas de 1924, con lo cual la ley estadounidense se consolidó como el instrumento legislativo más influyente en la política marítima internacional de aquella época. Además, a nivel nacional, la ley Harter sirvió de inspiración a otros países cargueros de entonces, tales como Canadá (Water Carriage of Goods Act de 1910) o Australia (Sea Carriage of Goods Act de 1904) entre otros. Otros casos cercanos a esa época se tienen en Nueva Zelandia (1903), Japón (1910) y Marruecos (1919).

17 Como ya hemos señalado, las RHW representan el más extendido reglamento internacional sobre el transporte marítimo internacional de mercancías. En este sentido, sobre él se ha escrito abundantemente tanto en obras generales y monografías, como en artículos. A lo largo de este apartado habremos de seguir primordialmente las dos primeras clases de documentos. Sin embargo, habremos de referirnos a algunos de los artículos más relevantes; de entre ellos véase los índices del IDM, pp. 1101 y ss. 
va del organismo británico especializado en materia de transporte marítimo, el Imperial Shipping Committee, al recomendar la elaboración de una legislación uniforme en la materia para todo el imperio británico, cuya flota mercante ocupaba el primer puesto a escala mundial. ${ }^{18}$

En el foro internacional, la iniciativa surgió de la International Law Association que, durante su Conferencia de La Haya de agosto-septiembre de 1921, aprobó el texto de lo que a partir de entonces se conocería como las Reglas de La Haya. En el proceso de elaboración del instrumento se buscó plasmar los intereses múltiples del sector naviero, cargador, asegurador y bancario. Las Reglas de La Haya articulaban un sistema de libre aceptación por los sujetos contratantes del transporte marítimo de mercancías, y reducían su ámbito de aplicación a los siguientes supuestos: ${ }^{19}$

- Transportes efectuados en régimen de conocimiento de embarque, con lo cual quedaba excluido el transporte en régimen de póliza de fletamento. Además no se regulaban las operaciones anteriores a la carga de las mercancías, ni las posteriores a su respectiva descarga.

- Posibilidad de que el porteador marítimo renunciara a las cláusulas de exoneración de responsabilidad, para asumir en cambio mayores obligaciones respecto al cargador.

Como bien sintetiza el profesor Ray, los transportistas tenían su responsabilidad regulada de acuerdo con las características que rodeaban al transporte internacional por agua, y se les admitía la irresponsabilidad por las culpas náuticas del capitán y tripulantes, por deficiencias del estado de navegabilidad del buque si se había empleado la diligencia razonable para ponerlo en condiciones, la exoneración por falta de marcas o deficiencia del embalaje de la carga, entre otros supuestos. La limitación cuantitativa de la responsabilidad se centraba en una cifra tope por bulto o unidad de transporte. Por su parte, para los banqueros se reducían y uniformaban las cláusulas del conocimiento; para la simplificación de la función de los aseguradores se precisaba el esquema de riesgos; para los

18 Cfr. con Scrutton, T., op. cit., nota 11, pp. 225 y ss.; Carver, T., op. cit., t. I, pp. 9 y ss.

19 Cfr. con Ray, Domingo, op. cit., nota 14, pp. 385 y ss., y Blas, Osvaldo, op. cit., nota 7 , pp. 336 y ss. 
titulares de la carga se suprimían las cláusulas de irresponsabilidad y se establecía la responsabilidad — limitada — del porteador basada en una cantidad, siempre que no se hubiera abonado el flete ad valorem. ${ }^{20}$

Las ventajas del nuevo sistema hicieron eco tanto en asociaciones nacionales e internacionales de derecho marítimo como en agrupaciones de navieros; con lo que se desarrolló un movimiento por procurar elevar su jerarquía de un simple instrumento de aplicación voluntaria a un ordenamiento legislativo internacional. Así, luego de una conferencia internacional celebrada en Buenos Aires en 1922, donde se aprobaron algunas enmiendas a la versión de 1921, se acordó trabajar para efectuar la celebración de una conferencia diplomática que las aprobara. ${ }^{21}$

El estudio más profundo del texto de las Reglas de La Haya llevó al sector de los cargadores a pugnar por un instrumento que tuviera un alcance determinante en la tutela de sus derechos. Sin embargo, la influencia del sector naviero y la importante labor uniformadora del CMI dieron lugar a la esperada conferencia diplomática en Bruselas que culminaría el 25 de agosto de 1924 con la firma de la Convención para la Unificación de Ciertas Reglas en Materia de Conocimientos, conocida como la Convención de Bruselas de 1924 o bien como las Reglas de La Haya, en atención a su texto original. ${ }^{22}$ La Convención entró en vigor el 2 de junio de 1931.

Para bien o para mal, debido a su amplia ratificación, a su incorporación o influencia determinante en el derecho interno de diversas naciones, y a su común designación en los formularios tipo de conocimientos de embarque como el régimen aplicable, este sistema es, a la fecha que escribimos, y pese a las críticas que válidamente pueden hacérsele, el auténtico ordenamiento del transporte marítimo internacional de mercancías. $^{23}$

20 Ray, Domingo, op. cit., nota 14, pp. 385 y ss.

21 Cfr. con Brunetti, Antonio, op. cit., nota 7, pp. 290 y ss.; Blas, Osvaldo, op. cit., nota 7, p. 337.

22 Idem.

23 Debe advertirse que la Convención de Bruselas de 1924 ha sido modificiada en un par de ocasiones por dos protocolos, el más importante de 1968, y el otro de 1979. En función de dichas enmiendas, algunos Estados han venido denunciando el instrumento original para adherirse a las versiones reformadas. Este es el caso, por ejemplo, de Dinamarca (1984); Finlandia (1984); Italia (1984); Japón (1992); Holanda (1982); Noruega (1984); Suecia (1984); el RU (1977) y otros. Entre los Estados que se han inspirado en la 
Luego de casi medio siglo de su aprobación, el CMI, organismo impulsor de su gestación original, aprobó en Rijeka en 1959 un proyecto de revisión de la Convención de Bruselas de 1924. Luego de la constitución de un comité de expertos, y de las diversas reuniones celebradas en Londres, París y Estocolmo entre 1960 y 1963, se logró precisar el texto modificatorio sometido a la Conferencia Diplomática que habría de sesionar en Bruselas entre 1967 y 1968. De dicha conferencia se consiguió la aprobación del protocolo modificatorio el 23 de febrero de 1968, conocido comúnmente como las Reglas de La Haya-Wisby (RHW), en donde se vinculó la antigua denominación con la tradición maritimista de la ciudad de Wisby, en Gotland, lugar donde realmente se aprobó el proyecto de Estocolmo de 1963 que serviría de base para la citada conferencia diplomática. ${ }^{24}$

Entre las reformas a la Convención de 1924 se encuentran aspectos relativos a: su ámbito de aplicación que debe entenderse como exclusivo del transporte internacional; la limitación cuantitativa de la responsabilidad del porteador, que pasó de 100 libras oro a 10,000 francos oro; la prórroga del término de prescripción; el reconocimiento de avances tecnológicos en el transporte, como la utilización de paletas y contenedores; el valor probatorio del conocimiento de embarque en manos de terceros, y otros temas de relevancia que estudiaremos a lo largo de esta sección. ${ }^{25}$ El protocolo entró en vigor el 23 de junio de 1977.

Por último, en consonancia con el abandono del parámetro oro como método de conversión del Fondo Monetario Internacional, las RHW fueron adaptadas de acuerdo al Protocolo firmado también en Bruselas el 21 de diciembre de 1979, con lo cual se concretó el límite cuantitativo de la responsabilidad del transportista marítimo en 667.67 unidades de cuenta, consistentes en derechos especiales de giro por bulto o unidad o a 2 uni-

Conferencia de 1924, podemos citar entre otros: Inglaterra (1924); Australia (1924); Bélgica (1928); Holanda (1927); Francia (1936); EUA (1936); Suecia (1936); Noruega (1938); Finlandia (1939); Italia (1942); España (1949).

24 Véase Blas, Osvaldo, op. cit., nota 7, p. 338. Como bien dice el profesor Blas Simone, se optó por nominar así al ordenamiento enmendado, rindiendo con ello homenaje a Wisby, y especialmente destacando las Leyes de la Ciudad de Wisby, Gothlandia, vigentes desde 1407 en Europa septentrional, que influenciaron el posterior derecho marítimo nórdico, hoy sin duda uno de los más avanzados del mundo.

25 Véase Blas, Osvaldo, op. cit., nota 7, p. 338; Ray, Domingo, op. cit., nota 14, pp. 393 y ss.; Ruiz, José, op. cit., p. 711. 
dades de cuenta por kilogramo de peso bruto de las mercancías perdidas o dañadas, aplicándose el límite más elevado. ${ }^{26} \mathrm{El}$ protocolo entró en vigor el 14 de febrero de 1984.

En virtud de que, salvo lo antes mencionado, el contenido sustancial del Protocolo de 1968 y el del Protocolo de 1979 es básicamente el mismo, la referencia al sistema unificado de estos dos instrumentos, en lógica adición de la Convención de 1924, es conocido y aquí lo designaremos también como las Reglas de La Haya-Wisby o RHW. ${ }^{27}$

\section{Aproximación al sistema de las llamadas Reglas de Hamburgo de 1978}

Luego de casi cuatro décadas de la entrada en vigor de la Convención de Bruselas, algunos países cargadores iniciaron una importante dinámica de oposición en bloque a la continuación del régimen que aligera la responsabilidad de los porteadores marítimos, claramente diseñado por las RH y confirmado por las RHW. En este sentido, el llamado "grupo de los 77", conformado básicamente por países en desarrollo que aglutina hoy mucho más que 77 naciones en el seno de la ONU, elevó formalmente su protesta en la Conferencia de la UNCTAD, celebrada en Nueva Delhi en 1968. La agrupación de Estados argumentó que el régimen del transporte marítimo internacional de mercancías resultaba marcadamente inequitativo e insatisfactorio para sus economías, por lo que resultaba necesario crear un nuevo sistema tendente a reducir los costos propios del transporte y fomentar con ello su comercio exterior. ${ }^{28}$

Con base en estas válidas inquietudes, la Uncitral, a solicitud de la UNCTAD acordó en 1969 la integración de un grupo internacional de trabajo dedicado a la reglamentación internacional del transporte maríti-

26 Véase RHW, artículo 4.5.

27 Es este sistema, integrado por los tres instrumentos de referencia al que nuestro país se ha vinculado internacionalmente con fecha 20 de mayo de 1994; según publicación en el DOF del 25 de agosto de 1994.

28 Véase UNCTAD, "Consecuencias económicas y comerciales de la entrada en vigencia de las Reglas de Hamburgo", en Transporte multimodal..., cit., pp. 26 y ss.; Ray, Domingo, op. cit., nota 14, pp. 504 y ss.; Blas, Osvaldo, Las reglas de Hamburgo..., cit., pp. 16 y ss. Un excelente análisis jurídico de las implicaciones de los instrumentos legislativos internacionales en la estructura de costos del transporte marítimo, puede encontrarse en Arroyo, Ignacio, op. cit., nota 5, pp. 229 y ss. Véase además O’Oloughlin, Carleen, The Economics of Sea Transport, Oxford, Pergamon, 1967, pp. 33 y ss. 
mo, conformado por delegados de 21 países, que tuvo como objetivo real formular un proyecto distinto técnica y económicamente al esquema de las RH, consolidado después por las RHW. ${ }^{29}$

El grupo de trabajo sesionó en ocho ocasiones, hasta que en 1975 reunido en la ciudad de Nueva York en febrero de 1975 presentó el proyecto a Uncitral, quien aprobó el proyecto y lo sometió a la consideración de una conferencia diplomática reunida en Hamburgo (de ahí que se conozca internacionalmente como Reglas de Hamburgo - Rha-) donde se celebró su firma por quince países el 31 de marzo de $1978 .{ }^{30}$ Sin que se haya estipulado un tonelaje mínimo para su entrada en vigor, las RHa

29 Véase Ray, Domingo, op. cit., nota 14, p. 506; Blas, Osvaldo, op. cit., nota 7, pp. 339 y ss. El grupo internacional de trabajo constituido bajo auspicios de Uncintral quedó integrado por delegados de Argentina, Australia, Bélgica, Brasil, Chile, Egipto, Francia, República Federal Alemana, Ghana, Hungría, India, Japón, Nigeria, Noruega, Polonia, Singapur, URSS, RU, Tanzania, EUA y Zaire. La participación de México fue a través de un grupo consultivo integrado además por delegados de EUA, Holanda, Noruega y la URSS, que tuvo por finalidad fomentar un acuerdo general respecto a los delicados puntos concernientes al fundamento y la limitación de la responsabilidad, así como al de la pérdida del derecho a la limitación de la responsabilidad del porteador marítimo. Ahora bien, entre las consideraciones que motivaron los trabajos del Comité se encontraban: a) Por su antigüedad, la Convención de Bruselas no responde ya a las soluciones requeridas por el transporte marítimo moderno; b) Esa Convención implicaba una elevación en el costo del transporte a través de figuras como la doble cobertura de seguro tomada por un lado por el titular de las mercancías para el caso de pérdida o de avería, y también por el porteador por su responsabilidad en tales casos; c) La Convención de Bruselas diseñó un sistema de responsabilidad claramente favorable para los países porteadores, normalmente países altamente desarrollados, y perjudicial para los países cargadores, comúnmente países en vías de desarrollo.

30 Idem. Los países que en esa fecha suscribieron el instrumento fueron República Federal Alemana, Brasil, Chile, Ecuador, Ghana, Madagascar, México, Panamá, Portugal, Santa Sede, Singapur, Venezuela y Zaire. Como bien señala el profesor Blas Simone, en la Conferencia de Hamburgo pudieron establecerse tres grupos bien definidos: el de los países desarrollados, el de los países en desarrollo, y el de los países comunistas. La ruptura de los bloques se manifestó con la aprobación del proyecto por Estados pertenecientes al primer grupo como Canadá, EUA, Francia, Noruega, Suecia, Finlandia y Australia; así como por Estados del tercero como Checoslovaquia y Hungría. Por otra parte, países pertenecientes al tercer grupo como Bulgaria, Polonia y la URSS, siguieron la votación de los países occidentales que formaban el primer grupo. Así, si bien existió una auténtica fisura de criterios homogéneos en la Conferencia, lo cierto es que las RHa no han recibido el mismo apoyo, y en consecuencia vinculación internacional de los importantes países que votaron en favor del proyecto original. Véase Blas, Osvaldo, op. cit., nota 7, p. 340 . 
iniciaron su vigencia luego de la vinculación de una veintena de Estados el 1o. de noviembre de $1992 .{ }^{31}$

Se considera que aproximadamente la mitad del texto de las RHa se ha tomado directamente de las RHW; mientras que gran parte del texto restante se ha tomado del llamado Sistema Varsovia del transporte aéreo internacional y del Convenio CMR sobre transporte carretero internacional, con lo cual la normativa de las RHa en realidad no es ajena al mundo del transporte de mercancías. ${ }^{32}$

Como antes se advertía, las variantes de las RHa en relación a la Convención de Bruselas, y en general a las RHW, tienen al menos una doble connotación. Por una parte, la técnica jurídica empleada en su formulación procuró abandonar el elevado casuismo inherente al Common Law que en definitiva fue el sistema que elaboró los antiguos instrumentos, para buscar centrarse en las categorías y conceptos más precisos del sistema romano-germánico propio de los países del llamado Civil Law. ${ }^{33}$

Por otra parte, es también evidente el cambio de perspectiva del binomio político y económico que inspiró el proyecto, por lo que los proyectistas buscaron asimilar lo más posible el régimen de responsabilidad del transportista marítimo al del resto de los porteadores de los otros modos internacionales de transportación de mercancías. Así pues, como sintetiza Ruiz Soroa, se adoptó el sistema de responsabilidad por culpa pre-

31 De los Estados que se han vinculado internacionalmente a las RHa por aceptación, aprobación o adhesión de conformidad con su artículo 30.1 no se obtiene ni en lo individual ni en el conjunto una proporción significativa en el tráfico marítimo mundial, razón por la que hasta hoy la importancia cuantitativa de este instrumento es bastante reducida en comparación con el sistema de la Convención de Bruselas de 1924 y sus protocolos modificatorios. Entre los estados que se han vinculado a las RHa se encuentran: Austria, Barbados, Bostwana, Burkina Faso, Camerún, Chile, República Checa, Egipto, Gambia, Georgia, Guinea, Hungría, Kenya, Líbano, Lesotho, Malawi, Marruecos, Nigeria, Rumania, Senegal, Sierra Leona, Tanzania, Túnez, Uganda y Zambia. Como puede verse, muchos de los países firmantes - incluido el caso de México- no han ratificado las RHa. A lo largo de este apartado, así como del epígrafe en donde estudiemos la responsabilidad del transportista a la luz de las Rha, citaremos algunos de los estudios doctrinales o institucionales más relevantes. A nuestro parecer, entre los más firmes análisis críticos de las RHa se encuentra el de Tetley, William, The Hamburg Rules - A commentary, LMCLQ, 1979, pp. 1 y ss.

32 Cfr. con UNCTAD, "Consecuencias...", cit., nota 28, p. 27.

33 Ibidem, pp. 26 y ss. Véase además Chorley \& Giles, op. cit., pp. 321 y ss.; Rodiere, René, op. cit., nota 10, pp. 388 y ss.; Ruiz, José, op. cit., nota 25, pp. 711 y ss.; Lefebvre, Tullio \& Pescatore, op. cit., pp. 636 y ss. 
sunta y la abolición de casos de exoneración como el de las faltas náuticas; se amplió el periodo de responsabilidad; se posibilitó la reclamación de los daños contra los porteadores efectivos; y se resolvieron problemas puntuales en los transportes sucesivos. ${ }^{34}$

Ante un cambio tan relevante del régimen de responsabilidad, el sector naviero y el de sus aseguradores de responsabilidad, los Clubes de Protección e Indemnización $(P \& I C l u b s)$ por distintas razones que a lo largo de este capítulo veremos, marcaron tajantemente su oposición a las RHa, pero de algún modo reaccionaron para evaluar el sistema de las RHW para considerar modificaciones menos radicales que las contenidas en las RHa.

Como ahondaremos al analizar los caminos hacia una tercera vía, entre otros organismos, el CMI, una de las organizaciones internacionales de carácter privado con mayor prestigio y tradición en la elaboración de proyectos de tratados internacionales en materia marítima, retomó las inquietudes de los sujetos críticos de ambos sistemas - RHW y Rha- a través de la creación de un subcomité internacional para la uniformidad de la regulación del transporte marítimo de mercancías, que fue presidida por el profesor italiano Francesco Berlingieri.

El trabajo específico de esta organización consistió en canalizar las sugerencias realizadas mediante cuestionarios a las asociaciones nacionales de derecho marítimo adscritas a él, para de ahí intentar sistematizar las alternativas concretas de modificación de las RHW, integrando las categorías y esquemas que se consideraran mejores sin trascender de dónde provinieran las posibles soluciones. ${ }^{35}$

Como puede advertirse, salvo lo que resulte del trabajo de Uncitral que veremos más tarde, los esfuerzos por la necesaria uniformidad internacional del transporte marítimo hasta ahora no han logrado los frutos esperados, con la consecuente falta de seguridad jurídica para todos los participantes del tráfico marítimo. En este sentido al momento coexisten en vigor los instrumentos propios del sistema original de la Convención de Bruselas de 1924 (RH) y sus protocolos de enmienda de 1968 y 1979 (RHW), ordenamientos que como se ve, se encuentran a su vez fraccionados por la división de los Estados ratificantes, que pese a todo conservan una misma línea general de regulación.

34 Ruiz, José, op. cit., nota 25, p. 711.

35 Véase la secuencia de los trabajos del subcomité del CMI en el Anuario de 1996, op. cit., pp. 343 y ss. Véase en ese mismo texto los avances de Uncitral en la materia. 
Por otra parte como hemos señalado, se encuentran también en vigor desde finales de 1992 las RHa de 1978, que si bien no han recibido un apoyo importante, representan un avance técnico sustancial que ha cuestionado fuertemente a toda la comunidad marítima internacional.

A lo largo de los próximos apartados habremos de analizar con mayor detalle la normatividad sobre responsabilidad del transportista marítimo de cada uno de los dos grandes sistemas representativos: las RHW y las RHa. De su seguimiento, el lector podrá ir cayendo en cuenta de sus diferencias, y de los puntos positivos o negativos que caracterizan el texto de cada uno. Como hemos expresado en otras ocasiones, la solución del estado de las cosas no puede precipitarse, sino surgir como resultado de una seria reflexión de la problemática global del transporte de mercancías.

No debemos caer en el error de precipitarnos irreflexivamente en favor de uno u otro de los sistemas hoy vigentes, pues es imprescindible que haya un consenso real y suficiente entre los sectores enfrentados; y éste acuerdo sea avalado por la mayor parte de Estados posible a través del ejercicio de Uncitral. Así, el estado de la cuestión, nos parece prudente esperar con sano espíritu crítico los resultados finales del proceso iniciado por el CMI, y seguido por Uncitral, para analizar después la actitud de los gobiernos de algunos países relevantes tanto por su potencia cargadora como porteadora, y sólo hasta entonces optar decididamente por la mejor alternativa que en forma global apoye a nuestra economía. ${ }^{36}$

36 Nos parece que esperar prudentemente a los resultados de la Uncitral en torno a su objetivo de crear un marco más equitativo para los sujetos vinculados al transporte marítimo internacional; para de ahí analizar detallada y críticamente sus contenidos, así como las reacciones de países clave es el criterio más ordenado que puede seguirse. En este sentido, parece interesante que se detecten las reacciones de los miembros de la Organización para la Cooperación y el Desarrollo Económicos, de la cual México es parte desde 1994 (véase DOF del 5 de julio de 1994). Ello resulta de importancia, pues en el seno de la OCDE no sólo confluyen los países de economías más desarrolladas (Alemania, Australia, Austria, Bélgica, Canadá, Dinamarca, España, EUA, Finlandia, Francia, Grecia, Holanda, Irlanda, Islandia, Italia, Japón, Luxemburgo, México, Noruega, Nueva Zelanda, Portugal, RU, Suecia, Suiza y Turquía) sino también fuertes intereses complementarios de grandes potencias cargadoras y porteadoras. En efecto, nos parece que si la OCDE ha sido creada como un foro de consulta intergubernamental e intercambio de ideas y experiencias relacionadas con la política económica como es la política del transporte de mercancías de los países miembros, resulta necesario considerar sus estudios y recomendaciones. Además, por supuesto, será necesario complementar la opinión con 


\section{CLAVES DEL SISTEMA DE RESPONSABILIDAD DEL TRANSPORTISTA MARÍTIMO BAJO LAS REGLAS DE LA HAYA-WISBY (RHW)}

\section{1. Ámbito de validez}

Bien hace el profesor Georges Ripert en advertir a título general que ni la Convención de Bruselas (y tampoco las RHW) es aplicable a todos los transportes marítimos, ni a toda la duración de éste, ni a todas las mercancías transportadas. ${ }^{37}$ En este sentido, explica Blas Simone, el ámbito de aplicación de la Convención de Bruselas está determinado por una compleja interrelación de situaciones subjetivas, objetivas, temporales y geográficas. ${ }^{38}$

otros foros de carácter regional como los del Tratado de Libre Comercio de América del Norte (TLCAN) o la Asociación Latino Americana de Integración (Aladi), por mencionar sólo dos de ellos. Véase además lo conducente en el Acuerdo General del Comercio de Servicios (GATS), así como Witker, Jorge y Jaramillo, Gerardo, op. cit., pp. 128 y ss. Por último, cabe advertir que si bien la labor uniformadora del CMI ha sido a todas luces determinante para el avance del derecho marítimo internacional, no podemos dejar de recomendar la necesidad de ser críticos y profundamente analíticos con sus proyectos, ya que como valientemente expresa el profesor Arroyo, "de ese club de ricos, de inclinación preferentemente armadora, a duras penas puede florecer una normativa orientada a equilibrar la posición debilitada de los países del tercer mundo". Véase Arroyo, Ignacio, op. cit., nota 5, p. 262.

37 Véase Ripert, Georges, op. cit., nota 10, pp. 255 y ss.

38 Véase Blas, Osvaldo, op. cit., nota 7, pp. 343 y ss. Advertencia: conviene señalar de entrada que el centro de la regulación de las RHW se basa en los daños (averías particulares) o pérdidas de las mercancías, pero no asi en la demora o retraso en el cumplimiento del contrato de transporte, pues como decimos, no lo regula. Sin embargo, la práctica evidencia que cuando la entrega de la carga se retrasa, su titular puede sufrir graves perjuicios económicos como consecuencia del deterioro de la mercancía o incluso la pérdida de las mismas. Sin embargo, puede considerarse válidamente que si existe un deterioro o pérdida de la mercancía por el retraso en la entrega, o bien incluso no sufre ésta ninguno de tales daños por su demora, pero ésta es injustificada y su causa además - de ser aplicable directamente las RHW - no se encontraría en el catálogo de exoneraciones, parece que el transportista sí podría devenir responsable por el retraso; pero en nuestra opinión, nunca por arriba de los montos de limitación de las RHW. Esto debe interpretarse de tal modo, pues si la pérdida total tiene un límite máximo, por mayoría de razón, un retraso, por grave que sea (salvo el caso del incumplimiento fundamental del contrato, según después analizaremos) no podría ir más allá de dicho límite. Así pues, estaría validada una aplicación indirecta de las RHW, pues como se ha dicho, los casos en los que ocurren daños o pérdidas de las mercancías, ocasionan una aplicación directa de dicha normativa internacional. Véase en este sentido Ray, Domingo, op. cit., nota 14, pp. 422 y ss. 
De acuerdo a este criterio, el profesor argentino ha sistematizado su estudio agrupando dichas situaciones según deriven: de la instrumentación del contrato de transporte por la emisión de un conocimiento de embarque; de las aguas por las que se realice el transporte; de las mercancías transportadas y la forma de hacerlo; y del tiempo o periodo del transporte. En conclusión podemos hablar, como en cualquier otro ordenamiento, del ámbito de validez material espacial y temporal del régimen unificado de las RHW. Veamos:

\section{A. Ámbito material de validez}

Como expone el profesor Ruiz Soroa, el objetivo declarado de las RHW es apuntalar el valor en el tráfico comercial del título representativo de las mercancías transportadas por mar; con lo cual el punto focal que define su ámbito de aplicación es el mismo conocimiento de embarque. ${ }^{39}$

Se ha expuesto en distintas oportunidades que el contrato de transporte reviste una naturaleza consensual en oposición a formal, y que la exigencia de la emisión del conocimiento debe considerarse ad probationem y no ad solemnitatem o ad substantiam. En este sentido, hay que reconocer que el ámbito de aplicación, según el criterio aquí expuesto, debe encontrarse en la existencia real del contrato, más que en su formalización en un conocimiento o documento similar. ${ }^{40}$

Ahora bien, es cierto que siguiendo a la letra el texto de la Convención se entiende que ésta será aplicable a cualquier conocimiento expedido en uno de los Estados contratantes. Sin embargo, el solo criterio de la expedición del conocimiento no es suficiente para considerar la aplicación de la Convención, ya que como hemos expuesto en la sección pasada también se expiden conocimientos de embarque en virtud de pólizas

39 Ruiz, José, op. cit., nota 25, p. 713.

40 Véase, en este sentido, la ley francesa de 1966, modificada en 1986, que incorpora el contenido de la Convención de 1924. Cfr. con Rodiere, René, op. cit., nota 10, pp. 251 y ss.; Vialard, Antoine, op. cit., nota 10, pp. 408 y ss. Como precisamente expone el profesor Ruiz Soroa, uno de los grandes aciertos técnicos de las Rha, en oposición a las RHW, es regular el transporte marítimo per se y no per relationem a un documento determinado, como hacen las RHW siguiendo los criterios del Common Law. Véase Ruiz, José, op. cit., nota 25, p. 714. 
de fletamento, con lo que no les aplica esta regulación sino hasta que el fletador circulara el título en favor de tercero. ${ }^{41}$

Por otro lado, como claramente explica el profesor Arroyo Martínez, la práctica del fletamento enseña que el Convenio se aplica aun cuando no exista conocimiento de embarque. El socorrido supuesto sucede cuando las partes de un contrato de fletamento convienen a través de la simple inserción de una Cláusula Paramount en que el sistema de la Convención — $\mathrm{O}$ el de algún ordenamiento nacional que la incorpore - se aplique directamente a la póliza de fletamento. ${ }^{42}$

En relación al criterio que comentamos, la Convención establece su aplicación al contrato de transporte formalizado en un conocimiento o en cualquier documento similar que sirva como título para el transporte de mercancías por mar. Ya en el capítulo anterior estudiamos los documentos utilizados en función del transporte marítimo, con lo cual podemos señalar que nos parece que la norma de la Convención se extiende a todo título de transporte marítimo de mercancías con la condición de que pueda ser equiparado por su naturaleza y funciones al conocimiento de embarque. ${ }^{43}$

En cuanto al ámbito de aplicación en función del lugar de expedición del conocimiento de embarque, debe considerarse ésta a todo conoci-

41 Véase el apartado indicado en el capítulo anterior. Scrutton, T., op. cit., nota 11, pp. 296 y ss.; Arroyo, Ignacio, op. cit., nota 5, pp. 427 y ss.

42 Arroyo, Ignacio, op. cit., nota 5, pp. 246 y ss. Un estudio completo de la autonomía de la voluntad y la selección del derecho aplicable en el transporte marítimo internacional, a través de las llamadas cláusulas paramount, que en esencia son estipulaciones contractuales mediante las cuales las partes designan la lex contractus, puede profundizarse en Álvarez, Juan, op. cit., pp. 21 y ss. Véase, asimismo, Stone, Peter, The conflict of laws, Nueva York, Longman, 1995, pp. 183 y ss.; Siegel, David, Conflicts, Minnesota, West Publishing, 1993, pp. 307 y ss.

43 Aunque pueda ser cuestionable entre nosotros, parece admitirse - siguiendo a Ruiz Soroa- que, para efectos de la aplicación de las RHW, se consideren documentos similares al conocimiento de embarque los llamados documentos provisionales de recibido para embarque, las órdenes de entrega y los llamados conocimientos directos, de acuerdo a lo que de ellos hemos estudiado en el capítulo precedente. Asimismo, hay también coincidencia en no considerar como documento similar al c/e a la carta de porte marítimo, sin embargo, su aplicación podría obtenerse insertando en estos documentos una cláusula de remisión a las RHW. Véase Ruiz, José, op. cit., nota 25, pp. 713 y ss.; Brunetti, Antonio, op. cit., nota 7, pp. 324 y ss. 
miento relativo a un transporte de mercancías efectuado entre puertos pertenecientes a dos Estados diferentes cuando: ${ }^{44}$

- El conocimiento se otorgue en un Estado contratante.

- El transporte se efectúe desde el puerto de un Estado contratante.

- El conocimiento prevea que las disposiciones de la Convención o de otra legislación que le ha hecho efectiva regirán el contrato.

Por último, conviene comentar aquí respecto al transporte de animales vivos y de mercaderías sobre cubierta, que se excluye de la Convención de Bruselas de 1924. Sin embargo, ello no quiere decir que, sin contravenir normas imperativas, las partes puedan pactar una regulación especial o bien someter la lex contractu a cualquier ordenamiento legal, entre los que puede elegirse las RHW. ${ }^{45}$

\section{B. Ámbito espacial de validez}

Luego de una modificación pertinente del artículo 10 de la Convención de Bruselas de 1924, el Protocolo de 1968 confirma la aplicación exclusiva de su regulación al transporte marítimo internacional, ${ }^{46}$ requi-

44 RHW, artículo 10 modificado por el artículo 5o. del Protocolo (RHW) que deroga y reemplaza el artículo 10 de la Convención de Bruselas.

45 Véase RHW, artículo 1.c); Arroyo, Ignacio, op. cit., nota 5, pp. 251 y ss.; Ray, Domingo, op. cit., nota 14, pp. 431 y ss. Conviene recordar aquí que, si bien el transporte de mercancías peligrosas o de material nuclear no está prohibido o exceptuado expresamente del ámbito de las RHW, habrá que ceñirse estrictamente a lo ordenado por los convenios internacionales respectivos.

46 El antiguo texto, ya modificado, hacía una vaga referencia a cualquier conocimiento expedido en uno de los Estados contratantes. Por lo que ve al transporte mariti$m o$, debe primero reconocerse que en principio ha de entenderse el término a la luz del artículo $1 \mathrm{~d}$ ) que define al buque para el transporte de mercaderías por mar, y con ello, exclusivamente el transporte marítimo y no el fluvial, lacustre, o el realizado en otros cuerpos de agua distintos al mar. Sin embargo, las partes pueden designar como ley aplicable las RHW, con lo que sus soluciones serían aplicables a pesar de la diversa vía navegable. Los límites del ámbito de validez espacial de las RHW han sido convenientemente explicados por el profesor René Rodière al apuntar: "La Convention n'opère que dans les rapports internationaux. Mais il ne suffit pas d'introduire un élément international quelconque dans un contrat de transport pour qu'il soit régi par la Convention de Bruxelles. Ainsi un transport entre deux pays non signataires de la Convention, exécuté en vertu d'un connaissement émis dans un pays non signataire, n'y est pas soumis". Véase Rodiere, René, op. cit., nota 10, p. 309. 
riéndose que el viaje haya comenzado en un puerto de un Estado contratante, o bien que las partes hayan pactado la sumisión expresa a las RHW en el conocimiento de embarque mediante la inclusión de una Cláusula Paramount. ${ }^{47}$

\section{Ambito temporal de validez}

De conformidad con los factores políticos y económicos que las determinaron, la RHW no aplican a todo el periodo durante el cual el transportista marítimo posee las mercancías para su transporte; esto es desde la entrega hasta la restitución, sino a uno mucho más acotado: desde la

47 El estudio de las cláusulas Paramount (cláusulas de designación de ley aplicable conocidas como cláusulas principales, soberanas o gobernantes) escapa a los fines de este apartado; sin embargo, cabe destacar su importante función. En este sentido debemos reiterar la remisión a la excelente monografía elaborada al respecto por el profesor Álvarez Rubio, quien sobre ella concluye: "El objetivo y función de la cláusula [Paramount] podrá ser, bien una incorporación de tal normativa al contrato (alcance limitado que se deriva del tenor del artículo 10 del Convenio de Bruselas de 1924 en su redacción inicial), o bien una designación de éste como aplicable, sometiendo la relación contractual a sus disposiciones, que tienen carácter imperativo... Los efectos de las cláusulas Paramount bajo la vigencia del Convenio de Bruselas de 1924 en su redacción inicial son, sin duda, mucho más limitados que los derivados de su inserción en una relación contractual de transporte, regida por el Convenio revisado por el Protocolo de 1968 [RHW]. En efecto, en el primer supuesto, si una relación contractual quedaba objetivamente fuera del ámbito de aplicación de tal normativa uniforme, de forma que ésta sólo deviniera aplicable en atención a la presencia de una cláusula Paramount, tal normativa convencional no ejercería su primacía jerárquica sobre una eventual ley interna que resultara aplicable en defecto de elección, y cedería en todo caso ante las disposiciones imperativas de tal norma interna, al tratarse de una simple incorporación contractual. En cambio, bajo la vigencia del Protocolo de 1968, su carácter imperativo, que alcanza, por supuesto, al artículo 10 del Convenio, tiene como consecuencia que, al configurarse la cláusula Paramount como criterio válido y autónomo para determinar la aplicación de tal normativa convencional, la designación así operada primará en todo caso frente a las disposiciones de una ley interna. Es decir, permanece la libertad de las partes para decidir incorporar o no al conocimiento de embarque tal cláusula: se permite a las partes determinar a priori la ley aplicable a la relación contractual del transporte marítimo, eliminando así la operatividad de las normas de derecho internacional privado del foro, y tal elección, en caso de insertarse a través de la cláusula, tendrá la virtualidad de determinar la aplicación de esa normativa uniforme designada, al margen de la concurrencia o no de algún otro de los criterios objetivos previstos de manera alternativa en el precepto". Véase Álvarez, Juan, op. cit., nota 42, pp. 150 y ss.; Stone, Peter, op. cit., nota 42, pp. 183 y ss.; Siegel, David, op. cit., nota 42, pp. 307 y ss. Véase también Arroyo, Ignacio, op. cit., nota 5, pp. 246 y ss. 
carga de las mercancías a bordo del buque hasta su descarga, dejando con ello fuera todos los periodos terrestres que normalmente preceden y continúan del desplazamiento marítimo. ${ }^{48}$

Con ello, puede advertirse el fraccionamiento del contrato en dos fases distintas (operaciones marítimas y operaciones terrestres) sometidas a su vez a dos regímenes diversos de responsabilidad. ${ }^{49}$ Así, como bien indica el profesor Osvaldo Blas del seccionamiento en tres momentos previsto por las RHW, puede considerarse la aparición de tres figuras contractuales distintas: 50

- Contrato de depósito: comprendido desde que el porteador recibe las mercancías hasta que las mismas son, efectivamente, cargadas a bordo.

- Contrato de transporte: comprendido desde su carga en el buque hasta su descarga del mismo.

- Contrato de depósito: comprendido asimismo desde la descarga de las mercancías del buque transportador hasta su entrega al consignatario o a las autoridades competentes, según correspondiera.

48 Para ahondar en el tema del periodo de responsabilidad del transportista marítimo bajo las RHW, véase Morán, David, Extremos del periodo de aplicación mínimo en la $C B-P V$ (Convención de Bruselas-Protocolo de Visby sobre transporte de mercancías bajo conocimiento de embarque), Madrid, McGraw-Hill, 1998, pp. 61 y ss. Como hemos señalado antes, conviene advertir que la Iniciativa de Reformas a la LN se aparta de las RHW, precisamente en el importante punto del periodo de responsabilidad, equiparándolo así a las RHa con la respectiva violación a las RHW, en su carácter de tratado internacional. Véase artículo 117.

49 A diferencia de las RHW, artículo 1 e), las RHa, artículo 4o., expanden el periodo de responsabilidad del porteador marítimo, abarcando tanto la etapa durante la cual se encuentran propiamente bajo su custodia material, como en el puerto de carga, durante todo el transporte por agua y en el puerto de descarga. Véase Ruiz, José, op. cit., nota 25, p. 713. Como después expondremos con mayor detalle, la extensión del periodo de responsabilidad del porteador ha sido uno de los puntos que más ha convulsionado al sector naviero ante la consideración de aceptar las RHa, ya que el texto de ese instrumento en la práctica los condiciona a contar con la infraestructura humana y material suficiente en todos los puntos de origen y de destino en donde sus buques operen. Previsiblemente, el proyecto final del CMI buscará limitar a parámetros más estrechos el periodo de responsabilidad ampliado por las RHa.

50 Blas, Osvaldo, op. cit., nota 7, pp. 346 y ss. 
Así pues, en virtud de que las RHW disponen que el transporte abarca el tiempo transcurrido desde la carga de las mercaderías a bordo del buque hasta su descarga del buque, debe señalarse que es únicamente en el periodo intermedio (contrato de transporte marítimo en estricto sentido) en el cual la responsabilidad del porteador se encuentra regulada por dicho instrumento internacional. De lo anterior se concluye que la naturaleza de la responsabilidad del porteador en el primer y tercer periodos (contratos de depósito) es diversa de la del segundo, con lo cual debe ser convenida por las partes, y en su defecto aplicarse las normas del derecho mercantil general. ${ }^{51}$

\section{Sistema general de responsabilidad del porteador maritimo}

A manera de introducción, vale delinear el que el régimen de responsabilidad de las RHW y de las muchas legislaciones nacionales que la siguen - como es el caso de nuestra LN - es un régimen de responsabilidad por presunta culpa o negligencia en la causación del daño atenuado relevantemente en favor del transportista marítimo. ${ }^{52}$

Como hemos comentado antes, debido al cuño angloamericano de las categorías utilizadas en su regulación, basada en factores casuísticos y no en criterios precisos, el jurista de tradición romano-germánica tiene a su cargo la difícil tarea de interpretar los supuestos normativos a la luz de su génesis en el Common Law, para de ahí circunscribirlos con la ma-

51 Idem. Véase entre nosotros CCom., artículos 332 y ss.; Vázquez, Óscar, op. cit., pp. 179 y ss.

52 Véase, en general, RHW, artículos 3o. y 40. Como después veremos, el régimen de las RHa se fundamenta en la responsabilidad por culpa presunta, respondiendo el transportista marítimo por el daño generado mientras las mercancías se encontraban bajo su custodia, salvo que pruebe que la causa del daño es ajena a su propia negligencia o a la de sus empleados. A diferencia de las RHW, en las RHa no aparece un sistema radical de exoneración en favor del transportista. En general, pues como después concluiremos, mientras que las RHW presentan un claro particularismo de la responsabilidad del porteador que aleja al derecho de la navegación de los otros tres regímenes de transporte internacional de mercancías, las RHa encuadran adecuadamente en el sistema de responsabilidad del transporte de mercancías en general (véase RHa, artículo 5o.). Véase también Scrutton, Thomas, op. cit., nota 11, pp. 201 y ss.; Carver, T., op. cit., nota 18, pp. 97 y ss. 
yor cientificidad posible en el mare magnum de su sistema jurídico nacional. ${ }^{53}$

En términos generales puede afirmarse que en las RHW la responsabilidad del transportista marítimo se actualiza por la falta de diligencia razonable en el cumplimiento de su obligación fundamental de poner al buque en estado de navegabilidad para efectuar con seguridad el viaje contratado; así como por el incumplimiento de su obligación de lograr que el buque se encuentre en la aptitud suficiente para cargar las mercancías específicas del viaje en cuestión. ${ }^{54}$

La responsabilidad por defectos de navegabilidad — explica el profesor Ruiz Soroa - se asienta en la existencia de culpa por parte del naviero o de las entidades por él empleadas para el mantenimiento y control del estado del buque. El régimen de responsabilidad abandona la concepción de navegabilidad como garantía objetiva. Así, la carga de la prueba

53 Véase en el capítulo que antecede, nuestro esquema sobre las normas aplicables a los supuestos de derecho privado del derecho de la navegación.

54 El estudio profundo del estado de navegabilidad escapa a las características de este trabajo; sin embargo, es necesario establecer ciertos elementos de interés. Las características técnicas conocidas internacionalmente como seaworthiness y cargoworthiness se encuentran previstas por el artículo 4.1 en relación al 3.1 de las RHW. Según después detallaremos, la primera de estas aptitudes técnicas se basa en la diligencia suficiente para armar, equipar y aprovisionar al buque convenientemente para su utilización, en general, y para su servicio, en particular, para cada caso concreto, incluyendo con esto la documentación necesaria para la operación necesaria del buque. Por otra parte, la llamada "cargabilidad" se refiere más bien a la diligencia consistente en limpiar o poner en buen estado las bodegas, cámaras frías o frigoríficas, y todos los otros lugares del buque donde las mercancías se cargan, de manera que sean apropiadas a la recepción, transporte y conservación de las mercancías a transportar. Como explica el profesor Domingo Ray, en todos los contratos de utilización de buques se considera como principio fundamental que quien suministra el buque debe haber empleado la debida diligencia para ponerlo en condiciones de navegabilidad absoluta y relativa. Esto es, no sólo para la navegación desde un punto de vista abstracto y genérico, sino en concreto, en relación al viaje y al destino específico del contrato (véase Ray, Domingo, op. cit., nota 14, pp. 201 y ss.). Así pues, el transportista es responsable de toda pérdida o daño que sufran las mercaderías, si el buque no está en condiciones de navegabilidad al comenzar el viaje, por no haberse empleado la diligencia razonable para ello. La prueba de innavegabilidad está a cargo de quien la invoque, aunque acreditar la razonable diligencia empleada (prueba de la diligencia razonable) debe ser acreditado por el transportista marítimo. Como después veremos, el estado de navegabilidad integral es de tal manera importante, que de darse ciertas conductas extremas (de muy improbable actualización) en el porteador, podría incluso perderse el beneficio de la limitación de su responsabilidad, debiendo responder con todo su patrimonio. 
para acreditar el ejercicio de la razonable diligencia en la preparación del buque reacae sobre el porteador. ${ }^{55}$

Por otra parte - siguiendo también a Ruiz Soroa- puede considerarse cómo otra causa genérica, en la que se actualiza la responsabilidad del transportista marítimo de acuerdo a las RHW, deviene de los casos en que resultan daños y pérdidas por defectos o errores en las operaciones de carga y estiba de las mercancías, pero esto únicamente cuando sea el propio porteador quien haya asumido contractualmente la realización de dichas operaciones. Sin embargo, cuando los términos del contrato imponen la realización de la operación al cargador o receptor (de acuerdo a la cláusula free in out - FIO_-), desaparece en principio la posibilidad de imputar responsabilidad al porteador. ${ }^{56}$

A estos dos géneros de responsabilidad positiva del transportista marítimo, se contrapone un verdadero catálogo de excepciones que caracterizan el aligeramiento de responsabilidad con que las RHW favorece al sector naviero. Esta serie de elementos casuísticos será señalado en un apartado especial dentro de este mismo capítulo.

Ahora bien, acertadamente advierte la doctrina que la normativa uniforme de las RHW regulan únicamente los supuestos de infracción de la obligación de custodia de las mercancías que pesa sobre el porteador; esto es, los casos de daños, pérdidas o averías de las mercancías ${ }^{57} \mathrm{De}$ ahí que debe tenerse en cuenta que no se prevén los supuestos de incumplimiento o defectuoso cumplimiento de la obligación del transporte en cuanto al acto del desplazamiento, situación que se entiende regulada por las reglas propias de la lex contractu, esto es, por el resto de las estipulaciones previstas en el conocimiento de embarque. ${ }^{58}$

55 Ruiz, José, op. cit., nota 25, p. 719. Véase, en general, sobre el estado de navegabilidad, en Scrutton, T., op. cit., nota 11, pp. 82 y ss.; Carver, T., op. cit., nota 18, pp. 102 y ss.; Chorley \& Giles, op. cit., nota 33, pp. 193 y ss.; Healy \& Sharpe, op. cit., nota 11, pp. 496 y ss.; Blas, Osvaldo, op. cit., nota 7, pp. 347 y ss.; Ray, Domingo, op. cit., nota 14 , pp. 201 y ss.

56 Véase RHW, artículo 3.2; Ruiz, José, op. cit., nota 25, pp. 719 y ss. Como indica el autor, por entrañar consideraciones de seguridad navegatoria, las operaciones de estiba y desestiba son indelegables por el capitán.

57 A diferencia de las RHa (artículos 5.1 y 5.2), no resulta claro que en las RHW el retraso en la llegada de las mercancías pueda incluirse como daño resarcible por el transportista marítimo.

58 Véase RHW, artículos 3.6 y 4o. También, Ruiz, José, op. cit., nota 25, p. 718. 
En este sentido, la regulación del transporte internacional de mercancías por mar a cargo de las RHW se caracteriza por elementos característicos que separan el sistema general de responsabilidad del resto del derecho privado del propio derecho de la navegación. El profesor Blas Simone ha ordenado este sistema de responsabilidad con base en ciertos elementos característicos que nos parece oportuno esquematizar a manera de cuadro elemental de la responsabilidad del sistema de las RHW, para después desarrollarlo en el resto de esta sección: ${ }^{59}$

- Jerarquía de responsabilidad: establece una responsabilidad legal y de orden público (imperativa) aplicable únicamente durante el lapso del transporte que va desde la carga de las mercaderías a bordo del buque hasta su descarga del buque [artículos 1.e), 3.7 y 3.8].

- Conocimiento de embarque: impone al porteador el deber de expedir un conocimiento de embarque detallando las mercancías recibidas. Este documento habrá de servir para acreditar la presunción salvo prueba en contrario, que las mercancías fueron recibidas tal y como aparecen descritas en él [artículo 3.4].

- Responsabilidad por culpa: reconoce una presunción de responsabilidad culposa —en oposición a responsabilidad objetiva o absoluta - en la actuación del transportista ante la pérdida o el daño que sufrieran las mercancías transportadas [artículo 4.1].

- Carga de la prueba: ubica la carga de la prueba correspondiente sobre el porteador únicamente para los casos en que éste requiera acreditar el empleo de diligencia razonable cuando hubiere resultado una pérdida o daño derivado del mal estado del buque para navegar y cargar mercancías (seaworthiness y cargoworthiness) [artículo 4.1].

59 Blas, Osvaldo, op. cit., nota 7, pp. 347 y ss. Véase también el desarrollo en Tetley, William, op. cit., nota 31, pp. 375 y ss.; Longley, Henry, op. cit., nota 10, pp. 31 y ss.; Chorley \& Giles, op. cit., nota 33, pp. 274 y ss.; Carver, T., op. cit., nota 18, pp. 90 y ss.; Ripert, Geoges, op. cit., nota 10, pp. 255 y ss.; Rodiere, René, op. cit., nota 10, pp. 280 y ss.; Brunetti, Antonio, op. cit., nota 7, pp. 298 y ss.; Lefebvre, Tullio \& Pescatore, op. cit., nota 33, pp. 636 y ss.; Ray, Domingo, op. cit., nota 14, pp. 434 y ss.; Arroyo, Ignacio, op. cit., nota 5, pp. 242 y ss.; Ruiz, José, op. cit., nota 25, pp. 718 y ss. 
- Exoneración subjetiva: exonera consecuentemente de responsabilidad al porteador por haber empleado una debida o razonable diligencia en el caso que antecede [artículo 4.1].

- Exoneración objetiva: exonera de responsabilidad al transportista en caso de producirse alguna de las 17 causales previstas o bien alguno de los riesgos exceptuados o incluso la desviación razonable [artículos 4.1 y 4.4].

- Límite indemnizatorio: limita el monto de la responsabilidad del porteador cuando éste resultara efectivamente el responsable [artículo 4.5].

- Derogación convencional: permite la derogación convencional de la responsabilidad del transportista, siempre que fuera aumentada en favor del titular de la carga, pero nunca disminuyéndola [artículo 4.5].

\section{Tipología de la responsabilidad}

De conformidad con lo que a continuación expondremos, el régimen de responsabilidad configurado por las RHW debe entenderse como de carácter legal y de jararquía imperativa. ${ }^{60}$ Para efectos de ubicar el tema de la responsabilidad del porteador marítimo derivada del contrato de transporte internacional de mercancías es necesario recordar la esencia del contenido obligacional que éste asume y que determina el resto del contenido de la figura: trasladar y restituir son las operaciones que estructuran la ejecución del contrato. Así, claramente el porteador asume una responsabilidad ex receptum frente al titular de la carga.

Tanto los derechos y obligaciones elementales, como el consiguiente sistema de responsabilidad han sido recogidos y sistematizados por el le-

60 Véase Ripert, Georges, op. cit., nota 10, pp. 255 y ss.; Rodiere, René, op. cit., nota 10, pp. 280 y ss.; Vialard, Antoine, op. cit., nota 10, pp. 405 y ss. El profesor Geroges Ripert destaca la imporancia del tema de la responsabilidad, distinguiendo en este tema el carácter particular del transporte marítimo. Como bien describe, la responsabilidad del transportador fue regulada por la práctica de manera muy diferente al derecho común, y cuando intervino la Ley para reprimir ciertas prácticas consideradas abusivas, el ordenamiento no volvió a ubicar el transporte marítimo bajo el imperio del derecho común, sino que creó para él un derecho particular. En efecto, el sistema de responsabilidad del transporte marítimo - a través de las RHW - es una muestra del particularismo del derecho de la navegación. Sin embargo, como después veremos, esta razón de su particularismo se reduce en las $\mathrm{RHa}$, ordenamiento internacional que se alinea al régimen de responsabilidad del resto de los modos internacionales de transporte de mercancías. 
gislador internacional a través de las RHW. Esta remisión tiene una doble justificación que merece mencionarse. La primera de ellas surge de las necesidades de armonizar la regulación del comercio internacional a través de ordenamientos de igual dimensión; así la función uniformadora de las RHW busca cumplir esta misión. ${ }^{61}$

Por otra parte, se justifica regular la materia a nivel internacional por la masificación en la que se prestan los servicios en línea regular, instrumentándose con ello los derechos y obligaciones contractuales en documentos preimpresos por el porteador, con lo que el poder negocial de éste frente al porteador debe ser acotado por el orden público. Es así, como surge la normativa tuitiva de los intereses del titular de la carga. ${ }^{62}$

Así, por encontrarse dispuesto en un ordenamiento iuspublicista internacional que establece los específicos límites, factores, causas de exoneración y montos indemnizatorios a los que está obligado el transportista marítimo para con el titular de la carga perdida o averiada, debe afirmarse que el régimen diseñado por las RHW entraña una responsabilidad legal, por lo que de resultar aplicable este ordenamiento habrá que estar al ámbito integral de su contenido. ${ }^{63}$

Aunado a su carácter legal, ha de señalarse la importancia de considerar la jerarquía iuspublicista, obligatoria o imperativa de las RHW, y la consecuente responsabilidad de orden público del porteador, en el transporte marítimo internacional de mercancías en régimen de conocimiento de embarque. ${ }^{64} \mathrm{El}$ carácter imperativo del ordenamiento se pone de manifiesto al establecer la inderogabilidad convencional del sistema de responsabilidad establecido. ${ }^{65}$ Así, la voluntad negocial de las partes está

61 Véase la jurisprudencia italiana en la interpretación del régimen de responsabilidad del transportista marítimo, tanto a la luz de las RHW como del Código de la Navegación (artículos 422 y ss.). Righetti, Giorgio, CN..., cit., pp. 507 y ss.

62 Véase así Arroyo, Ignacio, op. cit., nota 5, pp. 231 y ss.; Blas, Osvaldo, op. cit., nota 7 , pp. 348 y ss.

63 Véase, en tal sentido, Ripert, Georges, op. cit., nota 10, pp. 255 y ss.; Rodiere, René, op. cit., nota 10, pp. 280 y ss.; Vialard, Antoine, op. cit., nota 10, pp. 405 y ss.; Blas, Osvaldo, op. cit., nota 7, pp. 348 y ss.; Ray, Domingo, op. cit., nota 14, pp. 387 y ss.; Ruiz, José, op. cit., nota 25, pp. 718 y ss.; Arroyo, Ignacio, op. cit., nota 5, pp. 238 y ss.; Chorley \& Giles, op. cit., nota 33, p. 167; Lefebre, Tullio \& Pescatore, op. cit., nota 33 , pp. 636 y ss.

64 Idem.

65 La inderogabilidad del sistema sólo queda excepcionado cuando se realice en favor del cargador según permite el artículo 5o. de las RHW. Ahora bien, el principio gene- 
acotada por la voluntad protectora y coincidente del legislador internacional y del nacional; debido a la elaboración normativa del primero y la aprobación constitucional del segundo. ${ }^{66}$

Sin embargo, la jerarquía de la responsabilidad del porteador marítimo está asimismo limitada al ámbito de validez de las propias RHW que hemos visto. De ahí que exclusivamente se extienda durante el periodo del transporte efectivo, en conjunción con el resto de los elementos del ámbito de validez integral de la regulación internacional.

\section{La responsabilidad por culpa presunta del transportista}

Al estudiar el conocimiento de embarque en el capítulo anterior, señalamos cómo las RHW confieren a este documento un valor probatorio como recibo de las mercancías entregadas al porteador para su transportación en relación con su estado aparente, cantidad o peso, números y marcas descritas. Sin embargo, como advertimos, esta presunción de veracidad es relativa y puede ser desvirtuada. De su pérdida o avería particular se infiere la responsabilidad por culpa presunta, pero no absoluta del porteador, ante su deber insatisfecho de transportación y restitución indemne de las mercancías a su titular. ${ }^{67}$

$\mathrm{Al}$ respecto, Blas Simone reflexiona que el paralelo de ambas presunciones (la de responsabilidad del transportista y la de veracidad del conocimiento) lleva a una consecuencia directa: relevar al reclamante (cargador, consignatario o titular de la carga) de tener que probar que los

ral de inderogabilidad se encuentra en el artículo 3.8 al establecer que: "todas las cláusulas, convenciones o acuerdos en un contrato de transporte que eximan al transportador o al buque de responsabilidad por pérdida o daños ocasionados a mercaderías por causas de negligencia, culpa o falta de cumplimiento a los deberes u obligaciones establecidos en este artículo, o atenuando dicha responsabilidad en otra forma que no sea la determinada en el presente Convenio, serán nulos y sin efecto y se tendrán por no puestos". Sin embargo, como después veremos, del artículo 3.8 in fine se sigue: "La cláusula de excepción del beneficio del seguro al porteador y cualquier otra cláusula semejante exonerarán al porteador de su responsabilidad".

66 Como bien indica Blas Simone, al citar al célebre jurista Savigny, las leyes imperativas o absolutas resultan ser siempre leyes de orden público en la pertinente aplicación legislativa nacional. Así, siguiendo también con Blas Simone a Fedozzi debe afirmarse que no se trata con esto de comprometer la organización jurídica de un país, sino de la observancia de una norma de orden público internacional que es adoptada por un régimen normativo nacional. Véase Blas, Osvaldo, op. cit., nota 7, p. 349.

67 RHW, artículo 4.1 en relación al 3.3. 
perjuicios que sufran las mercancías durante el transporte, constatados recién a su arribo (finalización del viaje), se originaron por culpa del porteador o de sus agentes. ${ }^{68}$ Con ello, estas dos presunciones relativas o iuris tantum se complementan entre sí y destacan el carácter subjetivo - en oposición a objetivo - de la responsabilidad del porteador marítimo.

Ahora bien, el mecanismo para desvirtuar la citada presunción consistente en que se han recibido las mercancías tal como figuraban descritas en el conocimiento de embarque, o bien de no haber sido descritas, para desvirtuar la presunción de haberlas recibido en buen estado, se consolida en la figura del aviso del daño o pérdida (notice of claim) que debe hacerse antes o en el momento de retirar las mercancías por quien tenga derecho a la recepción de las mercancías con arreglo al conocimiento, o bien, dentro de un plazo de tres días después de la entrega, si las pérdidas o daños no son aparentes. El aviso debe hacerse por escrito y en él ha de especificarse la pérdida o la avería particular sufrida, así como la naturaleza general de éstas. ${ }^{69}$

El retiro de las mercancías, omitiendo todo aviso, entraña una presunción salvo prueba en contrario de entrega indemne de las mercancías en la forma en la que éstas aparecen consignadas en el conocimiento de embarque. Sin embargo, el retiro de las mercancías sin ese aviso no importa que opere caducidad alguna, sino que únicamente vincula al consignatario a probar la avería particular o la pérdida sufrida, así como el monto de ello derivado, por el que se considera debe responder el transportista. ${ }^{70}$

68 Blas, Osvaldo, op. cit., nota 7, p. 350.

69 RHW, artículo 3.6. En todo caso, ante la pérdida o daños ciertos o presuntos, tanto el porteador como el receptor de las mercancías deben darse recíprocamente todas las facilidades necesarias para la inspección de las mercancías y la comprobación del número de bultos. Esta facultad de las partes para inspeccionar el estado integral de la carga ha dado origen al servicio de agentes de inspección conocidos internacionalmente como survey agent o surveyor, quienes cuentan con personal técnico calificado para inspeccionar y establecer el estado de las mercancías transportadas. Su función en el comercio internacional es de suma utilidad.

70 Véase Ray, Domingo, op. cit., nota 14, pp. 402 y ss.; Blas, Osvaldo, op. cit., nota 7, p. 351. La estricta práctica de las previsiones extremas en las llamadas notice-of-claim, ha sido llevada en diversas ocasiones a tribunales estadounidenses, según indica Henry Longley: "Notice-of-claim provisions were frequently construed strictly against cargo owner. For instance, it was held that a bill of lading requirement for the filing of a notice of claim was not satisfied by a letter to the carrier giving notice of loss or damage to the 
Por otra parte, las RHW sancionan las reservas si el estado de las mercancías se comprueba en sentido contrario a lo descrito en éstas en el momento de la recepción. ${ }^{71}$

\section{Esquema del catálogo de exoneraciones del transportista marítimo}

Antes hemos señalado que el sistema de responsabilidad de la Convención de Bruselas y en general del sistema de las RHW se sustenta en dos presunciones: la veracidad de los datos consignados en el conocimiento de embarque y la responsabilidad por culpa del transportista. Sin embargo, como también hemos advertido ya, el régimen de responsabilidad positiva del porteador a la luz de las RHW ha sido elaborado con una rotunda intención de atenuarla lo más posible.

Para cumplir esta finalidad, el legislador internacional creó una impresionante gama de causas de exoneración, o excepted perils - expresión inglesa tomada de la práctica del seguro marítimo- que si bien en nuestros días pueden válidamente llegarse a considerar en muchos casos como excesivas, son ahora, tanto a nivel internacional como a nivel nacional, las normas legales aplicables al transporte marítimo en régimen de conocimiento de embarque realizado por líneas regulares. ${ }^{72}$

Los supuestos de exoneración, como el resto de las RHW, son resultado del razonamiento jurídico del Common Law basado en el método del caso, por lo que su formulación legal parece encontrarse envuelta en un cierto tono asistemático para el jurista de tradición romano germánica. ${ }^{73}$ Sin embargo, gracias al esfuerzo sistematizador de lo mejor de la doctrina iusmaritimista latinoamericana, podemos hoy agrupar dichos su-

cargo, if the letter did ont specifically set out that — claim — was filed against the carrier for the loss reported". Véase Anchor Line v. Jackson, 9 F.2d 543, 1926 AMC 221 (2d Cir.); The Scantic, 40 F.2d 39, 1930 AMC 899 (5th Cir.). Longley, Henry, op. cit., nota 10 , p. 200.

71 RHW, artículo 3.6.

72 Véase Carver, T., op. cit., nota 18, pp. 154 y ss.

73 El profesor Arroyo Martínez ha caracterizado acertadamente el sistema del Common Law que tanta importancia tiene en el campo del derecho marítimo, y que sin duda es necesario comprender para captar la realidad del tráfico jurídico y comercial del negocio marítimo. De acuerdo con el prestigiado autor español, las notas características son: a) La creación judicial del derecho, b) El precedente judicial vinculatorio, y c) La relevancia del procedimiento. Arroyo, Ignacio, op. cit., nota 5, pp. 43 y ss. Véase también Rockwell, Frederic, op. cit., pp. 264 y ss. 
puestos, e intentar partir de esa labor para realizar un estudio más claro sobre el problema. ${ }^{74}$

Para después pasar a su estudio, señalemos primero que las categorías sistematizadas por el profesor Blas Simone pueden, con fines didácticos, esquematizarse de la siguiente forma:

\section{A. Exoneración por hechos propios del porteador maritimo (la debida diligencia)}

- Poner al buque en estado de navegabilidad.

- Armarlo, equiparlo y aprovisionarlo convenientemente.

- Preparar, adaptar, limpiar y poner en buen estado las bodegas, cámaras frigoríficas, tanques y demás partes del buque cuando se carguen las mercancías para su recepción, transporte y conservación.

B. Exoneración por hechos de los dependientes del porteador marítimo (la culpa náutica)

- Errores en la navegación del buque.

- Errores en la administración del buque.

- Cláusula de negligencia.

C. Exoneración por casos de fuerza mayor, por hechos de terceros, por situaciones relativas a la carga, por causas innominadas y por desvio de ruta

- Casos de fuerza mayor (incendio, peligros de mar, actos de Dios, hechos de guerra, hechos de enemigos públicos, detención o actos

74 La sistematización a la que nos referimos, se debe al profesor argentino Blas, Osvaldo, op. cit., nota 7, pp. 351 y ss. Entre otros estudios elaborados por juristas de tradición romano-germánica, véase Brunetti, Antonio, op. cit., nota 7, pp. 298 y ss.; Lefebvre, Tullio \& Pescatore, op. cit., nota 33, pp. 636 y ss.; Ripert, Georges, op. cit., nota 10, pp. 255 y ss.; Rodiere, René, op. cit., nota 10, pp. 280 y ss.; Vialard, Antoine, op. cit., nota 10, pp. 405 y ss.; Ray, Domingo, op. cit., nota 14, pp. 387 y ss.; Diez, Alberto, op. cit., nota 7, pp. 294 y ss.; Fariña, Agustín, op. cit., pp. 78 y ss.; Vigier, Agustín, op. cit., nota 7, pp. 601 y ss.; Ruiz, José, op. cit., nota 25, pp. 718 y ss.; Arroyo, Ignacio, op. cit., nota 5, pp. 238 y ss. 
de príncipe o embargo judicial, cuarentena, huelgas o lock outs, motines o tumultos civiles, salvamento o tentativa de salvamento de vidas o bienes en el mar.

- Hechos del cargador.

- Situaciones relativas a la carga.

- Causas innominadas.

- Desvío de ruta.

\section{La limitación cuantitativa de la responsabilidad del transportista marítimo}

Una vez cristalizada en las RH la idea que en la Harter Act había quedado in germen respecto a la fijación de una limitación monetaria, en la Convención de Bruselas se concretó un acuerdo entre los distintos sectores del negocio marítimo para establecer un límite cuantitativo a la indemnización por daños o pérdidas a las mercancías que los porteadores marítimos habrían de pagar a los titulares de la carga, a cambio de que abandonaran las cuestionables prácticas de las cláusulas de irresponsabilidad. ${ }^{75}$

El límite indemnizatorio tiene un carácter ex lege y originalmente se cifró en 100 libras esterlinas valor oro por bulto o unidad de carga, parámetro de valor conocido como unidad de cuenta que, como hemos comentado, mutó primero al franco Poincaré y finalmente a los Derechos Especiales de Giro -DEG- (Special Drawing Right —SDR-), como hoy se conoce. ${ }^{76}$

La actualización del límite de indemnización, luego de los protocolos de 1968 y 1979, se ha fijado en 666.67 DEG por bulto o unidad, o bien en 2 DEG por kg. de peso bruto de las mercancías perdidas o dañadas aplicándose de ambos límites, el que resulte más elevado.

La Convención de Bruselas no estaba muy cerca de prever el futuro auge de la carga unitarizada ni su causa en el desarrollo tecnológico a

75 Véase Ripert, Georges, op. cit., nota 10, pp. 268 y ss.; Rodiere, René, op. cit., nota 10, pp. 313 y ss.; Lefebvre, Tullio \& Pescatore, op. cit., nota 33, pp. 649 y ss.; Longley, Henry, op. cit., nota 10, pp. 216 y ss.

76 Así las RHW, artículo 4.5, a partir de los protocolos modificatorios de 1968 y 1979 de la Convención de Bruselas de 1924; ordenamientos - todos ellos- a los que México se ha vinculado, según ya hemos señalado ( $D O F$ del 25 de agosto de 1994), y que han influido de modo determinante nuestra LN, artículo 104 y conexos. 
través de contenedores o paletas. Así, luego de valorar los litigios que se planteaban por el concepto bulto o unidad en el Protocolo de 1968, por fin se reguló la agrupación, consolidación o "unitarización" de mercancías mediante estos u otros instrumentos similares. ${ }^{77}$ Con ello, se considera que existen tantos bultos o unidades según enumere el conocimiento como incluidos en aquéllos; de no ser enumerados, entonces habrían de considerarse como un único bulto. ${ }^{78}$

Ahora bien, el mecanismo por el cual el cargador puede evitar verse sometido a los límites de las RHW es optar por hacer una declaración expresa que debe figurar en el conocimiento de embarque del valor de las mercancías. En virtud de que el porteador no podrá beneficiarse del límite como ordinariamente lo haría, la declaración consignada de tal valor trae consigo la elevación del flete; es así como surge el llamado flete ad valorem. Es por esta razón que, a pesar de que el cargador puede hacer uso válidamente de este derecho, en términos económicos resulta poco atractivo y consiguientemente es una práctica infrecuente. ${ }^{79}$

\section{Pérdida del beneficio de la limitación cuantitativa de la responsabilidad del transportista marítimo (la falta personal)}

El beneficio de la limitación cuantitativa de la responsabilidad de los transportistas, al que por ley tienen derecho a acceder éstos, es un claro privilegio al que no están legitimados si ha incurrido en conductas extremas. ${ }^{80}$

77 RHW, artículo 4.5 c). Véase los variados casos de jurisprudencia angloamericana en "limitations per package" en Chorley \& Giles, op. cit., nota 33, pp. 210 y ss.; Healy \& Sharpe, op. cit., nota 11, pp. 413 y ss. Véase también la jurisprudencia italiana sobre el llamado limiti del risarcimento, interpretando la normativa internacional y la nacional (CN, artículo 423), en Righetti, Giorgio, op. cit., nota 61, pp. 520 y ss. Por otro lado, Osvaldo Blas (op. cit., nota 7, pp. 370 y ss.) hace un interesante estudio sobre el cálculo del monto limitativo, sistematizando la aplicación de los términos bulto y unidad (package y unit).

78 Protocolo de 1968, artículo 2.

79 Véase Ruiz, José, op. cit., nota 25, p. 721.

80 El carácter privilegiado del beneficio es destacado por Chorley \& Giles (op cit., nota 33, p. 213) al señalar: "Limitation of liability is a privilege, which must not be enjoyed by the undeserving"; Longley, Henry, op. cit., nota 10, pp. 216 y ss. 
Antes de precisar el tema, recordemos que los porteadores marítimos se ven exonerados de toda responsabilidad - y consecuentemente de toda indemnización - derivada de los daños o pérdidas de las mercancías por el transporte, de acuerdo al catálogo de causas que hemos estudiado.

Ahora bien, de resultar según lo analizado, que por alguna razón ninguna de dichas causas opera válidamente para su exoneración, entonces ha de considerarse que el transportista deviene obligado a indemnizar, pero no el valor íntegro de los daños y perjuicios ocasionados al titular de la carga por el hecho dañoso (pérdida o avería particular), sino sólo hasta los límites con que la legislación internacional - y nacional- lo ha favorecido. Por las justificaciones que en su momento analizamos, el privilegio legislativo de la actividad, al menos en el ámbito de la responsabilidad, parece estar fuera de toda duda.

Como explica el profesor Ruiz Soroa, ante las dudas surgidas en torno a la aplicabilidad de la limitación en casos de daños o pérdidas por incumplimientos dolosos o gravemente culposos del mismo porteador, el Protocolo de 1968 sanciona que la pérdida del beneficio limitativo se produce cuando el daño sea resultado de actos u omisiones dolosas del porteador, o incurridas con dolo eventual por el mismo porteador. ${ }^{81}$

De acuerdo a la jurisprudencia británica, conviene puntualizar que la pérdida del beneficio opera también cuando ha ocurrido un incumplimiento fundamental del contrato (fundamental breach of the contract) que puede interpretarse en nuestro sistema como una inejecución grosera o dolosa de la obligación principal del contrato de transporte consistente en transportar las mercancías. ${ }^{82}$ Para que se considere ese grado extremo en el incumplimiento, debe atenderse a la figura del llamado dolo eventual que tiene su origen y equivalente como figura jurídica — según veremos - en la llamada willful misconduct del Common Law, sistema bajo el cual se elaboraron las RHW, que a su vez inspiraron a nuestra legislación — primero la LN de 1994 y ahora la LNCM del 2006-.

En efecto, el texto de las RHW señala categóricamente que "ni el porteador ni el buque tendrán derecho a beneficiarse de la limitación de responsabilidad establecida en este párrafo si se demuestra que los daños se deben a una acción u omisión del porteador que ha tenido lugar, ya

81 Ruiz, José, op. cit., nota 25, p. 721.

82 Véase, en este sentido, Ray, Domingo, op. cit., nota 14, pp. 479 y ss. 
con una intención de provocar daños, ya temerariamente y a sabiendas de que probablemente se producirán daños". ${ }^{83}$

Resulta interesante observar que la redacción utilizada en el Sistema Varsovia sobre transporte aéreo internacional es idéntico al que se establece en las RHW con lo cual el contenido conceptual general de la figura es similar en el campo del derecho marítimo y en el del derecho aeronáutico. ${ }^{84}$

Sin embargo, entre la regulación internacional de los otros modos de transporte - particularmente el aéreo-y la transportación marítima hay una diferencia importante que caracteriza a esta última. En efecto, mientras que en aquéllos la norma de pérdida del beneficio regula también las consecuencias del llamado dolo eventual (willful misconduct) ${ }^{85}$ de los empleados y agentes, y lógicamente también del porteador, las RHW únicamente se refieren a la conducta de este último sujeto, por lo que la cuestión se ha designado técnicamente como la falta personal (personal fault) del porteador.

Como vemos, para que de acuerdo a las RHW - y a nuestra legislación - opere válidamente la pérdida del beneficio de la limitación cuantitativa del porteador marítimo, es indispensable que el titular de la carga demuestre que los daños se deben a una acción u omisión de aquél (falta personal o personal fault) que ha tenido lugar, ya con una intención de provocar daños ya temerariamente (intentional or reckless disregard) y a sabiendas de que probablemente se producirán daños (dolo eventual o willful misconduct).

Así pues, de acuerdo al sistema judicial más versado en la interpretación de las RHW, la jurisprudencia británica, la falta que priva del beneficio de la limitación, por ser personal del responsable — cuando es per-

83 RHW, artículo 4.5 e).

84 Véase nuestro capítulo, al respecto, y Chorley \& Giles, op. cit., nota 33, p. 213.

85 Por el cuño angloamericano de las categorías jurídicas insertas en las RHW, una vez más es necesario evitar la traducción ad literam y acudir a la institución misma del Common Law. En este sistema se conoce en paralelo la willful and wanton misconduct como una conducta cometida con intencional o temeraria desatención de un deber necesario para la seguridad de la propiedad de un tercero. Así, según el prestigiado Black's Law Dictionary (op. cit., p. 1103), por esta categoría jurídica angloamericana debemos entender: "Conduct which is committed with an intentional or reckless disregard for the safety of others or with an intentional disregard of a duty necessary to the safety of another's property". 
sona jurídica - es la cometida, de acuerdo al acucioso estudio que hace el profesor García-Pita, por lo que se pudiera denominar una directing mind (mente directiva), cuyos actos pueden imputarse directamente a la persona jurídica a la que representa, pero hasta tal punto que sea actos llevados a cabo por la misma persona, de modo que la persona que actúe pueda considerarse como un alter ego de la entidad responsable. ${ }^{86}$

En definitiva — concluye García-Pita—, la jurisprudencia anglosajona ha señalado que ha de tratarse de algún miembro de su órgano de administración, o de quien pueda ser considerado un alter ego (factor o dependiente general, e incluso una sociedad personalista o una corporación - sociedad de capitales - la persona o personas a quienes haya sido delegada la representación y uso de la firma social) o de la persona a quien le haya sido delegada plenamente la gestión (administración o management) del buque - lo que incluiría el acto culposo del naviero-gestor, respecto de la responsabilidad de los condóminos del buque- e incluso los actos del propio capitán o tripulante, pero de forma excepcional: únicamente cuando ha habido negligencia en su nombramiento o en el acto de delegación de poderes; negligencia que suele manifestarse por la enorme gravedad del acto culposo del propio capitán. ${ }^{87}$

Como puede advertirse, por los extremos que necesariamente requiere para su válida actualización, la pérdida del beneficio de la limitación del porteador marítimo no es un supuesto frecuente. La ratio iuris se encuentra en la propia consecuencia de la norma internacional: tras la pérdida del beneficio de la limitación, el titular de la carga puede ejecutar su reclamación en todo el patrimonio del transportista que ha cumplido tan gravemente su obligación contractual.

86 El autor sistematiza la jurisprudencia y doctrina generada a partir de distintos casos, entre los que destacan los de los buques Lady Gwendolen, Garden City y Marriot. García-Pita, José, La limitación..., cit., pp. 224 y ss.

87 Idem. Debe recordarse que la determinación de los casos en los que un acto ha de ser considerado como acto personal del responsable es muy casuístico, por lo que se habría de analizar profunda y reflexivamente, valiéndose en lo conducente del derecho comparado (principalmente británico, por ser el inspirador de las RHW). 


\section{La acción indemnizatoria por las pérdidas o daños de las mercancías}

El problema de interpretación al que las RHW ha dado lugar en torno al tema de la prescripción de la acción de resarcimiento radica del sentido poco claro de su redacción: "sin perjuicio de las disposiciones del párrafo 6 bis, el porteador y el buque estarán en cualquier caso exonerados de absolutamente toda responsabilidad con respecto a las mercancías, a menos que se ejerza una acción dentro del año siguiente a su entrega o a la fecha en que deberían haber sido entregadas". ${ }^{88}$

Como bien dice el profesor Blas Simone, al no señalarse el carácter jurídico del instituto cabe preguntarse si estamos frente a un plazo de prescripción o de caducidad. Al respecto, conviene recordar que la prescripción extingue la acción dejando subsistente el derecho no ejercido, pero la caducidad aniquila el derecho. En general, el criterio se ha decantado por considerar que el texto se refiere a la primera de las figuras; esto es, al plazo de prescripción de la acción. ${ }^{89}$

En todo caso, y no obstante la regla general, el plazo citado puede ser prorrogado si las partes así lo acuerdan con posterioridad al hecho que haya dado lugar a la acción, dándose también mutuamente todas las facilidades razonables para la inspección de las mercancías y la comprobación del número de bultos. ${ }^{90}$

Ahora bien, como podrá observarse, las RHW únicamente ofrecen un cuadro elemental de normas de carácter adjetivo para ejercer la acción indemnizatoria, con lo cual todas las demás disposiciones procesales estarán a lo dispuesto por la ley adjetiva aplicable del tribunal que conozca del asunto según su competencia natural o porque a él se hayan sometido las partes expresamente.

88 RHW, artículo 3.6. El artículo 3.6 bis establece que las acciones de indemnización contra terceros [al contrato de transporte instrumentado en un c/e o documento similar] podrán ser ejercidas incluso después de haber expirado el plazo citado, si lo son dentro del plazo determinado por la ley del tribunal que conozca del caso. No obstante, ese plazo no podrá ser inferior a tres meses a partir del día en que la persona que ejerce la acción de indemnización haya pagado la cantidad reclamada o haya recibido una notificación de citación.

89 Blas, Osvaldo, op. cit., nota 7, p. 374.

90 RHW, artículo 3.6 in fine. 
La legitimación activa para incoar el proceso judicial o arbitral corresponde naturalmente al tenedor legítimo del conocimiento de embarque, pues es él el titular de la mercancía dañada o perdida. Esto es así porque la acción que lo legitima a la indemnización por el hecho dañoso es un reflejo del derecho que lo facultaba para exigir la entrega de las mercancías defectuosamente satisfecha de parte del transportista. ${ }^{91}$

Como veremos a lo largo de la segunda parte de esta obra, en virtud de la previa contratación de un seguro marítimo de mercancías, es también claro que el asegurador que indemnice por los daños que cubra la póliza queda subrogado ex lege en los derechos y acciones que correspondan al beneficiario contra terceros, por responsabilidad de éstos en los daños sufridos hasta el valor de lo pagado. ${ }^{92}$

Según comenta Ruiz Soroa, en los casos de transmisión limitada del conocimiento con fines de garantía, o como forma para legitimar a una empresa portuaria para la recepción, mediante el llamado endoso para recepción, coincidimos en que en principio se puede a admitir la legitimación del destinatario real, incluso si no es el cartularmente designado. ${ }^{93}$

La legitimación pasiva en las causas de transporte marítimo ha sido uno de los problemas más discutidos en el terreno procesal del derecho marítimo. El problema como ya hemos advertido antes, surge en el caso

91 Cfr. con Ruiz, José, op. cit., nota 25, pp. 721 y ss.; González, Rodolfo, Procedimientos maritimos, Madrid, Colex, 1996, pp. 103 y ss.

92 Así lo dispone el artículo 245 de la LNCM de 1963. En la siguiente parte de esta obra, veremos los distintos proyectos de adición a la $\mathrm{LN}$ en materia de seguro marítimo. De aprobarse la reforma, la LNCM quedaría finalmente abrogada.

93 Véase Ruiz, José, op. cit., nota 25, pp. 721 y ss.; González, Rodolfo, op. cit., nota 91, pp. 103 y ss. Por otro lado, consideramos que no ha lugar entre nosotros al seguimiento del criterio jurisprudencial español que tiende a extender la legitimación pasiva, con fines de responsabilidad, al agente consignatario del buque. En efecto, el agente naviero consignatario de buques (LN, artículo 19), según hemos visto, actúa en nombre del naviero u operador con carácter de mandatario o comisionista mercantil para todos los actos y gestiones que se le encomienden en relación a la embarcación en el puerto de consignación. Puede incluso estar legitimado para recibir notificaciones, aún de emplazamiento en representación del naviero u operador; pero en ningún caso debe interpretarse que estas facultades se extienden al grado de que deba responder con su patrimonio propio de las obligaciones de su mandante o comitente. Una tesis así, violenta la teoría general de la representación, y nos parece que no debe ser admitida en nuestro sistema. Véase las jurisprudencias del Tribunal Supremo Español de 2 de noviembre de 1983, 14 de febrero de 1986 y 10 de noviembre de 1993. 
de coexistir un porteador contractual (contractual carrier) y un porteador efectivo (actual carrier) en virtud de un contrato de fletamento subyacente, y debido también a que los vicios en la práctica marítima han llevado a que los conocimientos de embarque y documentos similares no sean llenados adecuadamente, surgiendo así el problema de identificar la identidad del transportista (identity of the carrier). ${ }^{94}$

Este problema ha sido originalmente solucionado en el derecho aeronáutico a través del claro distingo que la regulación internacional hace al respecto (Convenio de Guadalajara, México). Con inspiración en ese tratado - comentaremos más tarde-, las RHa a diferencia de las RHW también han contribuido al esclarecimiento de la situación al diferenciar a los dos sujetos porteadores. Así, las RHa organizan el régimen de responsabilidad de ambos mediante una sola solución. ${ }^{95}$

Por último, debemos admitir la complejidad del problema que se deriva si las RHW no regulan los temas fundamentales de jurisdicción y arbitraje; situación que en cambio es detalladamente articulada en las Rha. ${ }^{96}$ En principio parece que debemos admitir la libertad de los contratantes para convenir en ello. Sin embargo, no puede llegarse a la anarquía del ejercicio del forum shopping, por demás desarrollado fundamentalmente en beneficio de jurisdicciones preferentes a un sector. ${ }^{97}$

94 Véase Tetley, William, op. cit., nota 31, pp. 83 y ss.; Cashmore, Chris, Parties to a contract of carriage..., cit., pp. 3 y ss.; Longley, Henry, op. cit., nota 10, pp. 253 y ss. En virtud de que en las pólizas de fletamento se pacta una cláusula por la que el fletador se obliga con respecto al fletante por todas las reclamaciones que prosperen en su contra en función de la explotación del buque; y también en razón de que el fletante en ocasiones es una persona más fácil de identificar, los litigantes suelen dirigir sus acciones contra éste considerándolo como el porteador efectivo aunque realmente hayan contratado con el fletador (porteador contractual). Así pueden obtener — si su reclamación prospera - una cierta indemnización de manos del Club de P\&I (asegurador de la responsabilidad) del fletante, para que después, de conformidad con la póliza de fletamento, el fletador restituya las cantidades pagadas por aquél. Véase también Conlinebill 78, cláusula 17.

95 RHa, artículo 7o.

96 RHa, artículos 21 y 22.

97 El estudio en profundidad de la jurisdicción y el arbitraje internacional marítimos evidentemente escapan a nuestros objetivos en esta obra. Ambos son temas que al no ser regulados por el ordenamiento internacional aplicable (RHW) deben ser resueltos por el sistema del derecho internacional privado correspondiente. 


\section{CLAVES EN EL SISTEMA DE RESPONSABILIDAD DEL TRANSPORTISTA MARÍTIMO BAJO LAS REGLAS DE HAMBURGO (RHA)}

\section{Contexto}

Hemos señalado antes que, pese a que las RHa se encuentran en vigor desde noviembre de 1991, aún no han sido ratificadas por un número de Estados que en conjunto representen un volumen suficientemente significativo a escala mundial, en términos de carga a transportar o de tonelaje de sus flotas mercantes; nivel que por distintos motivos sí mantienen el conjunto de Estados que se han vinculado a la Convención de Bruselas de 1924 y en su caso, a los protocolos modificatorios. Advertimos también que México se ha adherido desde mayo de 1994 a las RHW y que nuestra LNCM del 2006 sigue el sentido de dicho ordenamiento internacional.

Las $\mathrm{RHa}$ representan un relevante avance técnico en la regulación del transporte marítimo, y su formulación sin duda alcanza niveles de equidad más altos que las RHW. ${ }^{98}$ Estas dos valoraciones, si bien son determinantes para una opción, no son las únicas a considerar, por lo que resulta indispensable ponderar reflexiva y críticamente las posiciones de dos subsectores que se necesitan y enfrentan de forma permanente: cargadores y porteadores marítimos.

Habrá que estar en todo caso a que, por su naturaleza, el transporte marítimo es una actividad de escala mundial donde las decisiones aisladas tienen sólo un resultado contraproducente, en tanto que las elecciones razonadas de la colectividad logran la imprescindible uniformidad internacional, situación benéfica para la economía global.

Conviene recordar, a título general, que el sentido fundamental de las RHa es desarticular los añejos particularismos del transporte marítimo aferrados a la normativa de las RHW, y alinear la regulación de esta actividad con la de los otros modos de transporte internacional. ${ }^{99}$

Bajo este contexto, debemos apuntar que un estudio profundo de las RHa escapa de los objetivos divulgativos de este artículo, por lo que parecería poco serio omitir la advertencia de que a lo largo de este apartado

98 Véase UNCTAD, “Consecuencias...”, cit., nota 28, pp. 26 y ss.; Blas, Osvaldo, Las reglas..., cit., nota 28, pp. 125 y ss.; Arroyo, Ignacio, op. cit., nota 5, pp. 229 y ss.

99 Véase, en este sentido, Chorley \& Giles, op. cit., nota 33, pp. 321 y ss.; Tetley, William, op. cit., nota 31, First Question, pp. 3 y ss. 
únicamente comentaremos grosso modo algunos de los rubros más interesantes y novedosos de este tratado en relación con las RHW. Habrá de tenerse en cuenta que algunas de las disposiciones de las RHa las hemos confrontado ya con normas específicas de las RHW.

\section{2. Ámbito de aplicación}

Explica, el profesor Blas Simone, que la normativa que delimita el ámbito aplicable en conjunción con el resto del Convenio, llevan a su autonomía formal en la formulación de los recíprocos deberes y derechos de las partes y en la interpretación judicial posterior de sus resultantes; situación que permite llegar a la desada uniformidad internacional a través de una sola normativa. ${ }^{100}$

Las condiciones previas que acotan el ámbito de validez de las RHa se reducen a dos elementos: el transporte de mercancías debe ser por mar y entre dos Estados diferentes. Con esto, su carácter exclusivamente marítimo (en estricto sentido) e internacional son claros. ${ }^{101}$ Ahora bien, los amplios factores alternativos específicos que determinan su aplicación obligatoria a dichos contratos de transporte (marítimos e internacionales) son los siguientes: ${ }^{102}$

100 Véase RHW, artículo 2o., en relación al 1o., 23, 30 y 31; Blas, Osvaldo, Compendio..., cit., nota 7, pp. 375 y ss. Cfr. con Ray, Domingo, op. cit., nota 14, pp. 503 y ss.; Ruiz, José, op. cit., nota 25, pp. 711 y ss.; Rodiere, René, op. cit., nota 10, pp. 307 y ss.; Chorley \& Giles, op. cit., nota 33, pp. 321 y ss.; Healy \& Sharpe, op. cit., nota 11, pp. 333 y ss.; Tetley, William, op. cit., nota 31, pp. 8 y ss.

101 Véase RHa, artículos 2.1 y 1.6. Así, importantes transportes de mercancías por agua que además son internacionales, como los realizados en los Grandes Lagos entre EUA y Canadá, estarían excluidos por ser transporte lacustre; igualmente se excluye su aplicación del transporte fluvial tan frecuente, por ejemplo, entre países centroeuropeos.

102 RHa, artículo 2.1. Como puede observarse de los primeros dos puntos ( $\mathrm{a}, \mathrm{b}$ y c) se consolida el criterio normativo clásico lex loci executionis. Es importante considerar que las RHa se alejan del llamado criterio instrumental que las RH estrictamente imponían para su aplicación: la existencia de un c/e. Por el contrario, se adopta un criterio objetivo enumerando las causas que ahora exponemos, sin sujetar su aplicación a la imprescindible existencia de un c/e. Véase Ruiz, José, op. cit., nota 25, pp. 713 y ss., quien correctamente señala la evolución de las Rha, al regular el contrato de transporte marítimo per se y no per relationem a un documento determinado. Véase también Blas, Osvaldo, Las reglas..., cit., nota 28 , pp. 23 y ss. 
- Que el puerto de carga o de descarga previsto en el contrato de transporte marítimo esté situado en un Estado contratante.

- Que uno de los puertos facultativos de descarga previstos en el contrato de transporte marítimo sea el puerto efectivo de descarga y ese puerto esté situado en un Estado contratante.

- Que el conocimiento de embarque u otro documento que haga prueba del contrato de transporte marítimo se emita en un Estado contratante. ${ }^{103}$

- Que el conocimiento de embarque u otro documento que haga prueba del contrato de transporte marítimo, estipule que el contrato se regirá por las disposiciones de las RHa o por la legislación de un Estado que dé efecto a esas disposiciones. ${ }^{104}$

Por otra parte, el ámbito personal de validez se generaliza al establecer que sus disposiciones se aplicarán sea cual fuere la nacionalidad del buque, del porteador (contractual), del porteador efectivo, del cargador, del consignatario o de cualquier otra persona interesada. ${ }^{105}$

Se establece también la exclusión expresa de su aplicación al transporte en régimen de póliza de fletamento. Sin embargo, cuando se emita un conocimiento de embarque en cumplimiento de un contrato de fletamento, las disposiciones de las RHa se aplicarán a ese conocimiento de embarque si éste regula la relación entre el porteador y el tenedor del conocimiento que no sea el fletador. ${ }^{106}$

103 Por esta norma (d) se prevé la aplicación de las Rha, aunque el país de destino para la descarga de las mercancías no sea parte contratante, pues la exigencia es unilateral con base en el documento que instrumenta el contrato de transporte.

104 Esta disposición hace posible la aplicación de las RHa para países que sin formar parte de ellas adopten sus soluciones. Esta disposición (e) debe complementarse con la obligación impuesta ante la emisión de un c/e o cualquier otro documento que haga prueba del contrato, de incluir en él una declaración en el sentido de que el transporte está sujeto a las disposiciones de las RHa que anulan toda estipulación que se aparte de ellas en perjuicio del cargado o del consignatario (artículo 23.3).

105 RHa, artículo 2.2. Como bien señala el profesor Blas Simone, ante el reclamo de una norma del país de la nacionalidad de las personas intervinientes o del país de la bandera del buque que limitaran o excluyeran la eficacia o esfera de aplicación de las RHa en razón de sus nacionalidades, se impondría el artículo 2.2 para evitar cualquier reenvío legal, asignándole categoría esencial a la autonomía formal que las mismas prevén para su imposición. Véase Blas, Osvaldo, Las reglas..., cit., nota 28, p. 21.

106 RHa, artículo 2.3. 
En cuanto al caso de embarques sucesivos, si éstos se prevén en el contrato durante un plazo acordado, se establece que las disposiciones del Convenio apliquen a cada uno de esos embarques. No obstante, cuando un embarque se efectúe en virtud de un contrato de fletamento, se aplica lo dicho en el párrafo que antecede.

\section{Definiciones}

Las RHa buscan definir los conceptos de porteador, porteador efectivo, cargador, consignatario, mercancías, contrato de transporte marítimo, conocimiento de embarque y el sentido de la expresión por escrito. Ya en nuestro capítulo anterior nos hemos referido a estas definiciones; valga sólo recordar aquí que a pesar de su propósito de claridad, éste no siempre se consigue, ya que en algunas de sus construcciones no se han integrado todos los elementos necesarios. ${ }^{107}$

\section{Rasgos y fundamentos del sistema de responsabilidad de las $\mathrm{RHa}$}

El sistema de responsabilidad de las RHa, basado en el principio de la culpa del transportista o de sus dependientes o agentes, ha sido sistematizado por el profesor Blas Simone con base en los siguientes rasgos generales: ${ }^{108}$

- Se mantiene el principio de culpa presunta del porteador.

- Se impone al porteador la obligación a lo largo de todo el transporte de mantener el estado de navegabilidad el buque y cuidar de las mercancías puestas a su cuidado (así se amplía el periodo de responsabilidad). ${ }^{109}$

107 Ibidem, artículo 1o. Debe recordarse que en el concepto de mercancía se incluye también a los animales vivos (véase artículo 5.5), lo que las RHW descartaban expresamente.

108 Véase Blas, Osvaldo, Compendio..., cit., nota 7, pp. 377 y ss. Entre los puntos en común, respecto a la estructura del sistema de responsabilidad, tanto de las RHW como de las Rha, se encuentran: a) La jerarquía de la responsabilidad es legal y de orden público; b) Establecimiento de una presunción relativa de que las mercancías fueron recibidas como aparecen descritas en el c/e; c) Presunción de responsabilidad culposa del porteador; d) Determinación de causales de irresponsabilidad; e) Limitación cuantitativa de la responsabilidad del transportista marítimo.

109 RHa, artículos 4.1 y 4.2. A diferencia de las RHW, el periodo de responsabilidad en las RHa se ha ampliado "de aparejo a aparejo" a "de puerto a puerto". Bajo el criterio 
- Se impone la carga de la prueba al transportista para acreditar las causales de su irresponsabilidad (origen de hecho dañoso y adopción de todas las medidas razonables para evitar su producción o sus consecuencias).

- Se eliminan como causales de exoneración de responsabilidad del porteador: la acreditación de la debida diligencia, las 17 causales contenidas en el artículo 4.2 de las RHW, así como el desvío de ruta.

- Se impone la carga de la prueba al titular de las mercancías para acreditar la producción del evento dañoso y que el mismo ocurriera durante el periodo de responsabilidad del porteador.

- Se condiciona la contribución a la avería común de las mercancías a que dicho deber no tenga su causa en un hecho culposo del capitán. ${ }^{110}$

- Se traslada la responsabilidad del porteador efectivo al porteador contractual, y se le responsabiliza por las acciones y omisiones de aquél y de sus empleados y agentes. ${ }^{11}$ Además tal responsabilidad es solidaria en los casos y en la medida en que aquéllos sean responsables. ${ }^{112}$

- Agregemos como un rasgo importante, el que se incluye como causa de responsabilidad el retraso en la entrega si el hecho se

de la UNCTAD, esto tiene por finalidad resolver el problema de la responsabilidad durante la manipulación de la carga que es cuando un porcentaje muy relevante de hechos dañosos se ocasionan. Con independencia del juicio valorativo que sobre el particular pueda emitirse, es notorio que las coberturas de los Clubes de P\&I —explica el profesor Morán Bovio - van más allá de la simple realización de las tareas de carga o descarga, así como de las operaciones que el porteador contrate realizar, y efectivamente realice; pues alcanza el periodo entre la entrega de las mercancías al porteador y la de éste al destinatario. En este sentido, se incluye el almacenamiento de los bienes previo y posterior a la aventura marítima, siempre que se relacione con ella de modo directo, así como las actividades que en el puerto realicen con la carga las personas de las que el porteador responde de uno u otro modo. Véase Morán, David, op. cit., nota 48, pp. 184 y ss.). Debe también tenerse en cuenta que el artículo 117 de la Iniciativa de Reforma a la LN, equipara la solución de las RHa a la LN, en violación de la RHW.

110 Así, en opinión del autor, con la norma del artículo 24.2 de las RHa se contradice la procedencia de la Regla D. de las Reglas de York y Amberes sobre la liquidación de la avería gruesa.

111 RHa, artículo 10.1.

112 Ibidem, artículo 10.4 
causó cuando las mercancías se encontraban bajo su custodia (en el periodo de responsabilidad señalado) a menos que se acredite la adopción de las medidas razonables para evitar el hecho y sus consecuencias. ${ }^{113}$

- Por último es de añadirse que a diferencia de las RHW, las RHa regulan detalladamente los rubros de la jurisdicción y del arbitraje. $^{114}$

Ahora bien, con base en estos rasgos, los fundamentos de la responsabilidad se centran en siete rubros que seguidamente enunciamos: ${ }^{115}$

- Responsabilidad por daños.

- Responsabilidad por retraso.

- Responsabilidad por pérdida o falta de entrega.

- Responsabilidad por incendio.

- Responsabilidad por transporte de animales vivos.

- Responsabilidad por el transporte indebido sobre cubierta.

- Responsabilidad concurrente. ${ }^{116}$

\section{Reclamaciones y acciones}

La parte V de las RHa está dedicada a la regular los rubros sobre avisos, prescripción, jurisdicción y arbitraje. ${ }^{117}$ La normativa en materia de avisos mutatis mutandi es similar a la contenida en las RHW. Sin embargo, se introduce como novedad la obligación del porteador (contractual) o del porteador efectivo de dar aviso al cargador de los perjuicios que sufran por culpa o negligencia del mismo o de sus empleados o agentes. De transcurrir el plazo señalado (90 días desde el hecho dañoso) sin haberse dado el aviso se ha de presumir, salvo prueba en contrario que el portea-

113 Ibidem, artículos 5.1 y ss.

114 Ibidem, artículos 21 y 22.

115 Ibidem, artículo 5o.

116 Bajo la regulación de este fundamento de responsabilidad, se autoriza la exoneración parcial del porteador marítimo si los daños a las mercancías transportadas derivaran de otras causales que no le fueran imputables. En opinión de Osvaldo Blas, dentro de ellas se incluye el caso fortuito y la fuerza mayor, el vicio propio o la merma natural de las mercancías, etcétera. Blas, Osvaldo, Compendio..., cit., nota 7, p. 385.

117 RHa, artículos 19 a 22. 
dor (efectivo o contractual) no han sufrido daños o pérdidas por culpa o negligencia del cargador o sus empleados o agentes. ${ }^{118}$

En relación a las RHW, las RHa extienden a dos años el plazo de prescripción de las acciones relativas al transporte de mercancías; salvo el caso de la avería común que por disposición especial se remite a la legislación nacional. ${ }^{119}$

Con el propósito de multiplicar las posibilidades de elección a conveniencia del titular de la carga, y frenar con ello los abusos de las cláusulas de jurisdicción, las RHa regulan el ejercicio de la acción, siempre de forma alternativa según considere dicho titular, ante un tribunal que sea competente de conformidad con la ley del Estado en que el tribunal esté situado y dentro de cuya jurisdicción se encuentre uno de los lugares siguientes: ${ }^{120}$

- El establecimiento principal o, a falta de éste, la residencia habitual del demandado.

- El lugar de celebración del contrato, siempre que el demandado tenga en él un establecimiento, sucursal o agencia por medio de los cuales se haya celebrado el contrato.

- El puerto de carga o el puerto de descarga.

- Cualquier otro lugar designado al efecto en el contrato de transporte marítimo.

Se establece asimismo la prórroga de la competencia de los tribunales de cualquier puerto o lugar de un Estado contratante donde se hubiera embargado el buque transportador o cualquier otro del mismo propietario para que, ante el mismo, el reclamante por daños a las mercaderías trans-

\section{Ibidem, artículo 19.7.}

119 Ibidem, artículos 20 y 24.

120 Ibidem, artículo 21.1. La vinculación de las normas sobre los rubros relativos a la ley aplicable y el tribunal competente en materia de transporte marítimo internacional de mercancías, hacen parecer que, en principio, a raíz de la ejecución del contrato debe estarse primeramente a la lex contractu aplicable, según la estipulación de las partes. Sin embargo, en el caso de que dicho pacto no se hubiere realizado o fuere inválido; entonces, de incoarse el procedimiento en un país ratificante de las $\mathrm{RHa}$ (por ejemplo, Chile) se aplicarían éstas. Sin embargo, de plantearse la reclamación ante un país que no lo es (por ejemplo, México) habría de aplicarse la normativa internacional que dicho país ha ratificado, en nuestro caso, las RHW. Véase Álvarez, Juan, op. cit., nota 42, pp. 21 y ss.; Ruiz, José, op. cit., nota 25, pp. 721 y ss. 
portadas ejerza su acción contra el porteador, quien podrá aceptar o no dicha elección, y optar porque ésta se radique ante uno de los tribunales antes citados previa fianza suficiente con que garantice el posible resultado del juicio. ${ }^{121}$

El carácter imperativo en la materia procesal es tajante en el sentido de prohibir que todo procedimiento quede incoado en relación con el transporte marítimo de mercancías regulado por las RHa, en un lugar distinto de los antes citados. Sin embargo, debe considerarse que esta norma no constituye obstáculo a la jurisdicción de los Estados contratantes en relación con medidas provisionales o cautelares. ${ }^{122}$

Además, las RHa reflejan claramente el carácter tuitivo al imponer al porteador su obligada comparecencia al juicio que le inicie el actor ante el tribunal competente que elija, sin posibilidad de una imposición contractual por parte del transportista. Sin embargo, una vez planteada la reclamación se permite que las partes acuerden continuar el juicio en un tribunal distinto al que originalmente conocía del asunto. ${ }^{123}$

Por último, el arbitraje fue otro de los rubros que pretendieron regularse en protección del sector cargador, habida cuenta de las imposiciones que en la materia venían realizando los porteadores. Siguiendo a Blas Simone, en las normas se concreta:

- La posibilidad de que las partes puedan pactar por escrito que toda controversia relativa al transporte de mercancías en virtud de las propias RHa sea sometida a arbitraje, con sujeción a su artículo 22.

- La imposibilidad para el porteador de extender el arbitraje al tenedor de un conocimiento de embarque adquirido de buena fe, derivado de un contrato de fletamento o donde se hubiera estipulado el sometimiento al arbitraje y no se incluyera esa disposición en el conocimiento emitido en consecuencia.

- Que el procedimiento arbitral podrá realizarse a elección del demandante en el Estado donde el demandado tenga su establecimiento principal o residencia habitual, en el lugar de celebración del contrato, en los puertos de carga o de descarga, o en cualquier otro designado en la cláusula compromisoria.

121 Ibidem, artículo 21.2.

122 Ibidem, artículo 21.3.

123 Blas, Osvaldo, Compendio..., cit., nota 7, p. 398. 
- La aplicación obligatoria de las disposiciones de las RHa por parte del tribunal arbitral o del árbitro designado.

- La aplicación obligatoria en los compromisos arbitrales de las disposiciones contenidas en el artículos 22.3 y 22.4 , declarando nula de pleno derecho cualquier cláusula incompatible con sus disposiciones.

- El reconocimiento de validez de un compromiso arbitral celebrado por las partes después de iniciado el reclamo basado en el contrato de transporte marítimo, aunque dicho compromiso contrariara las disposiciones contenidas en el mismo artículo 22.6. Por tal posibilidad ha de suponerse que el sometimiento de las partes a un compromiso arbitral está suscrito en forma voluntaria y su validez se ve aumentada porque debe haberse adoptado después de presentada la reclamación. ${ }^{124}$

\section{UNCITRAL Y LA BÚSQUEDA DE UNA TERCERA VÍA}

\section{Justificación para una tercera vía}

Si bien Uncitral ha sido exitosa en otros campos, como lo son la compraventa de mercaderías y el arbitraje comercial, en los cuales ha logrado verdaderamente un régimen uniforme; en el terreno del transporte marítimo su historial no ha sido tan afortunado.

En efecto, si bien las RHa - en las cuales Uncitral trabajó a solicitud de UNCTAD - entraron en vigor en 1992 y a la fecha aproximadamente 30 Estados son partes contratantes (siendo una tercera parte de ellos, países sin litoral), ni las grandes potencias comerciales, ni tampoco los Estados con mayores flotas parecen interesados en adherirse al instrumento.

Por otra parte, si bien la tasa de ratificación de las RHW -en sus distintas modalidades, según hemos descrito antes- es sustancialmente mayor, esto no quiere decir que un instrumento cuyo texto principal fuera elaborado hace cerca de un siglo sea, ahora, una respuesta efectiva a las necesidades del comercio internacional, al cual sirve la industria marítima.

124 El citado autor considera que, aunque el Convenio no lo dice, debe estimarse que tal reclamación debiera ser la judicial, en razón de la trascendencia que le otorga el mismo inciso 6. 
Tal vez el ejemplo más claro de la prácticamente nula eficacia de las RHA, y de la cada vez más tibia vigencia de las RHW en el tráfico internacional lo sea el hecho de que las dos potencias comerciales más grandes - EUA y China - que, de acuerdo a informes de la OMC para el año 2006, sobrepasan juntos la mitad del comercio mundial, en realidad no aplican del todo, ni uno ni otro sistema. ${ }^{125}$

Mientras EUA continúa — desde 1936 - la aplicación mediante su COGSA, basada en las Reglas de la Haya de 1921, China optó, a través de su Código Marítimo de hacer una formulación ecléctica y pragmática de las RHW y de las RHa, bajo un matiz de interpretación propio de sus sistema. Así, además de EUA y China, otros países han optado por practicar variaciones a los dos grandes sistemas internacionales, con lo cual, se hace patente que la uniformidad del régimen jurídico del transporte marítimo es francamente irreal y que la necesidad del cambio se impone.

A escasos cuatro años de haber entrado en vigor las RHa, ya la Uncitral reconocía — además de la falta de uniformidad internacional- los vacíos existentes en los dos regímenes respecto a la operatividad de los documentos de transporte y la consecuente problemática para el comprador, el vendedor y las entidades financieras participantes.

\section{Los primeros pasos}

A partir de la justificación anterior, en 1996, el Secretariado de Uncitral fue autorizado para entrar en consultas sobre trabajos pertinentes con organizaciones internacionales especializadas en el tema, tales como el Comité Marítimo Internacional (CMI), la Federación Internacional de Asociaciones de Transitarios (Fiata) la Cámara Naviera Internacional (ICS) y la Asociación Internacional de Puertos (IAPH), entre otras entidades del sector.

Lejos de encontrar en Uncitral una institución internacional rival, el CMI - a pesar de ser el tradicional foro defensor de los armadoresoptó por desarrollar un trabajo de análisis a cargo de un grupo de trabajo, mediante cuestionarios dirigidos a sus asociaciones nacionales de derecho marítimo en todo el mundo. A partir de los cuestionarios, un grupo de especialistas del CMI - destacando entre ellos Suart Beare y Francesco Berlingieri- lograron, mediante una apretada agenda de reuniones 
técnicas entre 1999 y 2001, acordar un Proyecto de Instrumento sobre Derecho del Transporte que fue entregado a Uncitral en diciembre de $2001 . .^{126}$

Al aceptar el proyecto del CMI, Uncitral decidió dejar prácticamente intacto el contenido, y referirlo así a su Grupo de Trabajo III, el cual inició a sesionar sobre el tema a partir de abril de 2002, bajo la presidencia del Rafael Illescas. Desde entonces, el Grupo de Trabajo sesiona de modo alterno dos veces por año, en Viena (otoño) y Nueva York (primavera). Si bien es cierto, que todavía hay temas sensibles por resolver, es probable que luego de finalizar las sesiones del Grupo de Trabajo, y tras la aprobación de Uncitral y de la Asamblea General de las Naciones Unidas se convoque a una conferencia diplomática que adopte el — todavía polémico — instrumento; probablemente para 2008. ${ }^{127}$

Como se verá en las conclusiones de este artículo, si bien es cierto que el régimen del transporte marítimo no ha logrado la uniformidad deseada para el comercio internacional, lo es también que ya hay una moderada certeza jurisdiccional y arbitral en la aplicación del sistema más ampliamente aceptado — las RHW-.

Así las cosas, si la incorporación de un nuevo régimen que no tenga probabilidad real de ser adoptado universalmente, lejos de coadyuvar con la uniformidad, generará mayor confusión en el tráfico comercial. Con ello, el reto por lograr un efectivo consenso internacional es fundamental para evitar la pulverización mayor del régimen jurídico del transporte marítimo.

Por otra parte, conviene tener presente que - como en otros muchos ámbitos - el iniciador del ejercicio de revisión ha sido EUA Como señala Michael Sturley, asesor principal de la Delegación de EUA en el Grupo de Trabajo III de Uncitral; ya desde antes de 2003, la Asociación de Derecho Marítimo de EUA inició un proceso de revisión parcial de COGSA con una ambición mayor: llevar a que EUA no solamente re-

126 Véase Hooper, Chester, "Two paths to same goal”, Journal of Commerce, septiembre de 2005.

127 Véase Estrella, José, "Brendan Brown Lecture Series: Unidroit Symposium: The Relationship between formulating Agencies in International Legal Harmonization: Competition, Cooperation, or Peaceful Coexistence? A few Remarks on the Experience of Uncitral", Loyola Law Review, núm. 51, verano de 2005. 
suelva internamente la controversia entre RHW y RHa; sino que incluso, lleve la solución al terreno internacional a través de Uncitral. ${ }^{128}$

Por una serie de razones propias de la política exterior de EUA, ese país suele participar, y comúnmente hacer presente su liderazgo, en muy diversas negociaciones de instrumentos internacionales, sin que llegue jamás a formar parte de ellos. Así, a pesar de que ha sido el país proponente de la revisión de los dos grandes regímenes internacionales, por interés de aplicar su modelo logístico al resto del mundo, de no llevar a cabo el ejercicio completo, que implicará en su momento la ratificación del instrumento internacional, no parece factible que el esfuerzo de más de diez años haya valido la pena.

Desde luego, actores fundamentales del comercio internacional, como China, Japón y la UE, si bien observan la necesidad de una reforma al sistema, que tienda a un régimen verdaderamente uniforme, parecen tener cierta distancia al proyecto, y antes de dar un paso trascendente - como lo es ratificarlo - esperarán que el liderazgo estadounidense durante la revisión de una década, se manifieste también en su interés oficial de vincularse al nuevo esquema.

Incluso, con la pronta vinculación de EUA y otros países, una vez en vigor, el instrumento requerirá de un tiempo de maduración — décadas quizás - para que mediante procesos jurisdiccionales y arbitrales en todo el mundo, se decante lo suficiente como para ser considerado, en la práctica, un mejor sistema y se ofrezca certeza jurídica suficiente a todos los actores. Valgan pues estas palabras de mesurado escepticismo para repasar algunos de los contenidos más interesantes del proyecto.

\section{Una aproximación al proyecto}

\section{A. Generalidades ${ }^{129}$}

Como se ha dicho, el desarrollo de las prácticas logísticas y comerciales, así como la tecnología, son los ejes que han puesto de manifiesto

128 Véase Sturley, Michael, "The United Nations Commission on International Trade Law's Transport Law Project: An Interim View of a Work in Progress", 39 Tex Int'l L.J. 65 , pp. 5 y ss.

129 El documento oficial consolidado de Uncitral — a la fecha de este artículo - que usaremos para el análisis de los siguientes epígrafes es: A/CN.9/WG.III/WP.56. Sin embargo, el listado completo de los documentos de la organización puede encontrarse en www.uncitral.org. 
hacer trascender los instrumentos anteriores. Así, no se trata simplemente de ajustar los contenidos existentes en las RHW o las RHa, sino de incorporar nuevos temas propios de la evolución técnica y comercial.

En este sentido, además de los temas tradicionales que hemos ya descrito respecto a los instrumentos anteriores, el proyecto cubre también transacciones electrónicas, documentos de transporte, transmisión de derechos, control efectivo y entrega al consignatario. Si bien estos temas son fundamentales en el transporte marítimo - y multimodal - de mercancías, hasta la fecha no han sido objeto de uniformidad internacional, con lo cual, el cúmulo de tratamientos solamente resta certeza a las partes interesadas en el transporte.

A continuación, describiremos algunos de los rubros más importantes del instrumento. Desde luego, es necesario recordar que es todavía un documento de trabajo, y si bien, cada área de discusión queda en principio cerrada por el Grupo de Trabajo, lo cierto es que no hay nada que restrinja ni a las delegaciones participantes en él, ni mucho menos a los participantes en la futura conferencia diplomática para practicar las reformas necesarias.

Una vez hecha la aproximación a los rubros generales del proyecto, nos detendremos en dos temas en los que - a nuestro parecer- existen todavía importantes áreas grises que representan contingencias para la eficacia del sistema: los llamados "contratos de volumen" y el tratamiento de las cláusulas de jurisdicción.

\section{B. Ámbitos de aplicación}

La extensión del ámbito espacial de validez ha tenido en cuenta la falta de certeza de los regímenes actuales, en los que la responsabilidad depende del lugar en que haya ocurrido el daño. Con el propósito de poner fin a esta incertidumbre, que de origen propicia litigios innecesarios, el Grupo tomó en cuenta las tres alternativas tradicionales ("puerto a puerto", "pluma a pluma" o "puerta a puerta") y propuso tener como base el sistema "puerta a puerta" pero con ciertos ajustes; lo que ha llevado a que el mecanismo del instrumento de Uncitral se conozca como "marítimo plus". 130

130 Entre los estudios del ámbito de aplicación del instrumento de Uncitral, véase Crowley, Michael; “Admiralty Law Institute Symposium: The Uniqueness of Admiralty 
En esencia, el tratamiento propuesto consiste en que cuando el transporte se ha documentado a través de un conocimiento de embarque que tenga en cuenta distintas modalidades de transporte, siendo una de ellas la marítima, las partes del contrato de transporte se entenderán sometidas a la regulación del Convenio, incluyendo el régimen de responsabilidad de éste, a pesar de que el daño haya ocurrido en la fase marítima o en el transporte terrestre.

Optar por una respuesta uniforme como la que se propone es especialmente importante en el tráfico de contenedores, en donde es complejo - y en ocasiones imposible - determinar la fase de transporte en donde ocurrió el daño, ya que el contenedor es abierto hasta su entrega en la fábrica o el almacén final del consignatario-comprador de las mercancías.

Tras cierto debate con los países europeos miembros de CMR y CIM-COTIF, los instrumentos internacionales de responsabilidad en transporte carretero y ferroviario, se adoptó una solución de compromiso: cuando pueda demostrarse que el daño ocurrió durante la fase del transporte de superficie y esa fase de transporte esté regida por un tratado internacional vinculante, entonces el régimen de responsabilidad aplicable es el de dicho régimen de transporte de superficie.

En lo que respecta al ámbito personal de validez, además de las partes del contrato de transporte marítimo (embarcador y "porteador contractual"), el Convenio regirá también la relación con aquéllos sujetos que sin mediar un contrato con el embarcador, efectivamente realicen una operación de transporte marítimo (el llamado "porteador efectivo") o de logística asociada a éste.

Esta solución evitará un vasto cúmulo de litigios en prácticamente todo el mundo, en donde la cuestión a determinar es si el porteador efectivo y los operadores vinculados a la logística marítimo-portuaria deben o no considerarse como regidos por las RHW.

Así pues, el consignatario claramente tendrá acción en contra del porteador efectivo, los operadores de las terminales marítimas y los estibadores. Así, a pesar del interés de exportadores e importadores en general, resultó inviable expandir el ámbito personal de validez a transportistas ajenos a la fase marítimo-portuaria. Con lo cual, los transportistas de superficie están excluidos del Convenio. of Goods by Sea: the Multimodal Problem”, Tulane Law Review, núm. 51, junio de 2005. 
Uno de los temas de más difícil negociación ha sido determinar qué transacciones deben quedar cubiertas por el Convenio y cuáles no. En el ejercicio hecho por el Grupo de Trabajo se han analizado respuestas a partir de tres aproximaciones independientes entre sí: documental (el documento de transporte efectivamente utilizado); contractual (el contrato celebrado entre las partes); y de tráfico (el tipo de tráfico, considerado como de línea regular o distinto a éste). ${ }^{131}$

El Grupo consideró que la práctica superaba el tratamiento independiente de cada una de las tres aproximaciones al problema y optó por generar una mezcla de éstas. Así, una vez excluida la importancia de la nacionalidad de bienes y sujetos, por una parte se hace referencia al lugar de recepción o de entrega; por otra se hace referencia a la voluntad de las partes a aplicar el Convenio o bien la aplicación del mismo por haberlo así declarado el Estado contratante. Por último, se excluyen expresamente de la aplicación del Convenio a los contratos de fletamento, todos los contratos de utilización de embarcaciones - incluidos los fletamentos de espacio- los contratos de servicio no regular (con excepciones), y los contratos de volumen (con excepciones).

Las exclusiones del ámbito de aplicación del Convenio son, desde nuestro punto de vista, un terreno muy delicado, pues no es difícil vislumbrar un escenario en donde los armadores, de la mano de grandes agentes transitarios diseñen mecanismos para evadir la aplicación obligatoria del Convenio. Desde nuestro punto de vista, habrá de tenerse especial cuidado con el desarrollo del proyecto en cuanto a los contratos de volumen.

Si bien se ha pensado en ellos como un vehículo adecuado para normar la relación contractual entre empresas que cuentan con similar grado de complejidad y poder de negociación, lo cierto es que, de no quedar debidamente constreñida la figura en el Convenio, en la práctica tratarán de considerarse como contratos de volumen a operaciones que en realidad no lo son, abusando así del pequeño embarcador y consecuentemente, del consignatario de las mercancías. En el análisis de la figura, co-

131 Véase Nikaki, Theodora, "The Uncitral Draft Instrument on the Carriage of Goods (Wholly or Partialy) (By Sea): the Treatment of 'Through Transport Contracts'”, Transport Law Journal, núm. 31, primavera-verano de 2004; Zekos, Georgios, "The Contractual Role of Documents issued under the CMI Draft on Transport Law 2001", Journal of Maritime Law \& Commerce, núm. 35, enero de 2004. 
mentaremos sus dificultades y las posibles formas de impedir la evasión de la aplicación obligatoria del Convenio.

\section{Régimen de responsabilidad del porteador}

Salvo la eliminación de la culpa náutica, el acotamiento parcial de la exoneración por fuego y algunas correcciones en materia de la carga de la prueba entre las partes litigantes, el régimen de responsabilidad del porteador es similar al existente en las RHW. ${ }^{132}$ Entre las innovaciones del régimen se encuentra el tratamiento en situaciones en las que el porteador deba considerarse como, sólo parcialmente, responsable.

En efecto, en una variedad de ocasiones es francamente imposible determinar la medida en la que el daño fue causado por el porteador. La solución propuesta por el Grupo consiste en establecer que el porteador será responsable del daño solamente en la medida en que haya contribuido a él. Es decir, aún en los casos en que efectivamente deba indemnizar por el daño, de acuerdo a los límites monetarios establecidos por el Convenio, estará en condiciones de defenderse indicando en qué medida el embarcador contribuyó al daño.

Si bien se trata de un tema todavía no totalmente cerrado, debe tenerse en cuenta que el tratamiento de las "demoras" puede quedar excluido del todo del Convenio - como en otros instrumentos sobre transporteo de incluirse, estarían tal vez solamente referidas a aquéllas demoras que tienen un carácter no razonable en el tráfico.

\section{Régimen de obligaciones del embarcador}

La sola referencia a las obligaciones en materia de mercancías peligrosas, hecha en las RHW, se considera ya como insuficiente, toda vez que la razón de ser de una logística efectiva lleva a que el embarcador deba asumir una posición más preactiva en la operación; lo cual conlleva un mejor servicio y reduce la probabilidad de daños en la carga.

Las obligaciones del embarcador son básicamente de información oportuna, pero también están referidas a las instrucciones que debe dar

132 Véase Tetley, William, "Reform of Carriage of Goods - The Uncitral Draft and Senate COGSA '99”, Tulane Maritime Law Journal, núm. 28, invierno de 2003; Hicks, John, "What Should we do with the Fire Defense, Late in the Evening?", Texas Law Review, marzo de 2005. 
al porteador con relación a la manipulación de la carga. Entre las categorías de información e instrucción, se encuentran previstas en el Proyecto: i) La información técnica referida a la manipulación y el transporte; ii) El deber de cumplimiento de cualquier norma que el porteador deba tomar en cuenta, considerando el tipo de viaje y el lugar de destino; y iii) La compilación de los datos necesarios del contrato y el título de transporte o el documento electrónico.

\section{E. Límites de responsabilidad}

Si bien no existe un acuerdo final sobre los límites cuantitativos de responsabilidad del porteador, nos parece que hay una clara tendencia a que sean sustancialmente mayores a los previstos en las RHW.133

Si bien es difícil predecir el rango del límite cuantitativo, no es impensable pensar que el piso de la negociación sean las RHa (1/4 superiores a RHW) y el tope lo sean otros instrumentos en materia de transporte de superficie, o incluso de transporte aéreo.

\section{F. Consideraciones generales sobre jurisdicción}

Las cláusulas de jurisdicción en los contratos de transporte marítimo en régimen de conocimiento de embarque es en una amplia variedad de supuestos un abuso de los porteadores y sus agentes. Obligar a los interesados en la carga a litigar en jurisdicciones distintas a las suyas, hace que éstos se vean obligados a simplemente no iniciar proceso alguno para ser indemnizados, o bien, a aceptar transacciones sumamente bajas propuestas por el porteador responsable del daño.

Es por ello que el tema sobre cláusulas de jurisdicción $-\mathrm{y}$ de arbitraje - ha sido especialmente sensible para prácticamente todas las delegaciones en Uncitral. El problema, sin embargo, es encontrar un mecanismo de uniformidad en el Convenio, pues particularmente las normas en la materia de la Unión Europea son relativamente flexibles entre los países comunitarios. En el epígrafe especial, analizaremos brevemente los esfuerzos del Grupo para encontrar una respuesta uniforme al importante problema del abuso de estas cláusulas.

133 Garza, Nicholas de la, Uncitral's Proposed Instrument on the International Marine Carriage of Goods, Transportation Law Journal, núm. 32, otoño de 2004. 


\section{Temas objeto de especial advertencia}

\section{A. Aproximación}

Durante 2004-2005, representé a México (Secretaría de Comunicaciones y Transportes, SCT) en el Grupo de Trabajo de Uncitral. Durante ese tiempo, en coordinación con mis compañeros de delegación, México manifestó el apoyo al trabajo de Uncitral; ello sin dejar de ver con preocupación cómo algunos temas fundamentales - como la adecuada regulación de los contratos de volumen y las cláusulas de jurisdicción- no habían sido suficientemente resueltos por el Grupo.

A partir de entonces, y ya desde el ángulo académico y del ejercicio privado, he mantenido el contacto profesional con la cancillería mexicana y con la SCT, con el fin de poner de manifiesto la importancia del proyecto. Sin embargo, también he mantenido mis advertencias sobre la necesidad de evaluar con detenimiento el proyecto, y en particular, aquéllos mecanismos que permitirían la evasión de normas obligatorias por parte del sector porteador, haciendo al Convenio totalmente intrascendente a las RHW y las RHa.

En efecto, la vigencia de un instrumento internacional que ofrezca - expresa o tácitamente - vehículos para burlar normas imperativas, que buscan dotar de mayor equidad a la relación entre porteadores y embarcadores sería francamente desafortunada, y representaría, incluso, un retroceso importante en el derecho marítimo contemporáneo. Como ha quedado anunciado, los dos temas más importantes que bajo nuestro punto de vista deben ser decisorios para apoyar o no de modo definitivo el Convenio son: la adecuada regulación de los contratos de volumen y de las cláusulas de jurisdicción.

\section{B. Los contratos de volumen}

Como señala Mary H. Carlson, jefa de la Delegación de EUA en el Grupo de Trabajo de Uncitral, si el Convenio pretende realmente progresar y responder a las necesidades cambiantes de la industria, debe esta- 
blecer, junto con un marco de normas generalmente aplicables, un ámbito de flexibilidad que las partes necesitan para ser exitosas. ${ }^{134}$

Si bien estamos de acuerdo con este postulado general, es importante esclarecer si la redacción actual del Proyecto es lo suficientemente sólida para evitar los abusos, y desde luego, entender antes las razones de inclusión de los contratos de volumen en el texto del Proyecto.

A diferencia de la práctica logística en la mayor parte del mundo, la industria de los porteadores marítimos y la de los grandes agentes transitarios en EUA desde hace más de una década ha venido marcando una tendencia a la desregulación de sus operaciones. La forma de hacerlo ha consistido en apartarse de las funciones tradicionales vinculadas al transporte marítimo, para ofrecer una serie de servicios vinculados al transporte - embalaje, consolidación, tramitación administrativa, etcétera- durante periodos de tiempo relativamente largos y con descuentos a partir del volumen de carga contratada en dichos periodos.

Así pues, parecería que esta gama de servicios ha desnaturalizado la figura misma del contrato de transporte marítimo en régimen de conocimiento regida por COGSA, logrando con ello, que una importante gama de operaciones quede a la libre contratación entre las partes, de modo que el régimen de responsabilidad estricta del porteador queda prácticamente eliminada, o si acaso, sustancialmente desdibujada, si se compara con los regímenes RHW y más aún en contraste con las RHa.

Desde un punto de vista pragmático, lo anterior no representa problema alguno cuando los contratantes - embarcador y porteador - tienen una capacidad de negociación similar y un nivel de complejidad adecuado como para tener una opinión profesional respecto al contrato que pretenden celebrar; además de una consultoría adecuada sobre evaluación de riesgos que los haga prever las situaciones derivadas de posibles siniestros, contratar las pólizas de seguro adecuadas, etcétera.

En la práctica, esta situación ocurre -y es por demás sano que exista - entre el porteador y una empresa exportadora mediana o grande que reúna dichas características de especialización; o bien entre el porteador marítimo y un gran agente de transporte y servicios logísticos integrales

134 Carlson, Mary, "U. S. Participation in the International Unification of Private Law: the Making of the Uncitral Draft Carriage of Goods by Sea Convention", Tulane Maritime Law Center, marzo de 2006, p. 14. 
(conocidos como Non-Vessel Operating Carriers, NVOC) como DHL, Fedex, UPS, etcétera. ${ }^{135}$

En el contexto de la apertura de negociaciones hacia un nuevo instrumento de Uncitral, la industria logística de EUA ha visto con agrado la apertura de una oportunidad comercial importante: llevar la práctica de sus contratos de servicios en tráficos regionales a un reconocimiento internacional, a través de los - hoy llamados - contratos de volumen. Esto es, fomentar la prestación de sus servicios logísticos integrales a exportadores de todos tamaños — principalmente medianos - con lo cual, al tener la posibilidad de contratar grandes volúmenes de carga proveniente de muchos exportadores, se logra una reducción significativa en el flete de los porteadores marítimos.

Si bien, como se ha mencionado, la incorporación de esta práctica estadounidense al ámbito universal, no tendría por qué impactar negativamente, exige una cautela extrema por parte de los negociadores del Convenio. De no contar con los candados suficientes, los porteadores marítimos bien podrían intentar caracterizar operaciones pequeñas de embarcadores - exportadores - no complejos como contratos de volumen, y por tanto, escapar de la regulación imperativa del Convenio, evadiendo con ello su régimen de responsabilidad.

La incidencia de los contratos de volumen dentro del Proyecto debe entenderse en tres eslabones: i) La definición de los mismos; ii) Su exclusión general del ámbito de aplicación del Convenio; y iii) El régimen especial de los contratos de volumen, en cuanto a los mínimos inderogables del Convenio, incluso para tal tipo contractual. Tras describir los elementos básicos — que no únicos — de cada uno de estos tres eslabones y valorar su operación conjunta, veremos si la redacción impone los suficientes candados para que no se abuse del régimen, según hemos alertado antes.

De acuerdo al artículo 1 b) del Proyecto por "contrato por volumen de carga" se entenderá todo contrato que prevea el transporte de cierta cantidad de carga, en una serie de remesas, durante cierto periodo de tiempo contractualmente estipulado. Cabrá estipular una cantidad mínima y máxima, así como una cierta escala de cantidades.

135 Gluk, Richard, NVOCCs and their Role in the International Multimodal Transport System; and Ohl, Kersten, NVOCCs and their Role in the International Multimodal Transport System, Simposio Marítimo, Barcelona, 1992. 
Como ya hemos adelantado, el artículo 9 1. d) del Proyecto excluye de la aplicación del Convenio a los contratos por volumen de carga; ello con ciertas limitaciones: i) por las cláusulas por las que se rija cada remesa transportada en el marco de un contrato por volumen de carga, en la medida en que así lo determine obligatoriamente el Convenio mismo; y ii) asimismo, en la medida en que dichas cláusulas del contrato por volumen de carga sean aplicables a alguna remesa que, pese a ser transportada en el marco de dicho contrato, se rija por el Convenio de acuerdo al inciso i) anterior.

Ahora bien, el Proyecto considera nulas una serie de estipulaciones que tiendan a la exclusión o limitación directa o indirecta del régimen imperativo del Convenio. Sin embargo, el caso de los contratos de volumen ha sido sujeto a un régimen especial. En este sentido, de acuerdo con el artículo 95 del Proyecto, el contrato podrá estipular deberes, derechos, obligaciones o responsabilidades que sean superiores o inferiores a lo prescrito en el régimen del Convenio, siempre y cuando el contrato por volumen de carga indique de forma explicita que en alguna de sus cláusulas se estipula una excepción al régimen del Convenio y siempre que haya sido personalmente negociado; o indique de forma explícita toda sección del mismo en donde se estipule alguna excepción al régimen del Convenio.

Si bien se establecen candados adicionales, como el señalamiento consistente en que ningún documento de transporte constituye por sí mismo un contrato por volumen de carga; así como la no incorporación de excepciones al régimen del Convenio por simples remisiones a otros documentos, como veremos hay todavía reductos que parecen no tomar en cuenta la probabilidad de los abusos al régimen.

Antes de tomar en cuenta esos posibles abusos, valga recordar que aún en el caso de celebrar contratos por volumen, existe una serie de obligaciones inderogables, como son mantener la navegabilidad de la embarcación; tripular, armar y avituallar debidamente al buque y mantenerlo así durante toda la travesía; las obligaciones del embarcador en materia de información e instrucciones sobre la carga, incluyendo las normas en materia de mercancías peligrosas; y la pérdida del derecho a limitar la responsabilidad del porteador (artículos 16, 28, 29, 30, 33 y 66).

Como hemos sugerido antes, desde nuestro punto de vista, el régimen de los contratos de volumen, si bien representa un avance para las operaciones a realizar por partes con similar poder de negociación y 
complejidad en la administración de riesgos y operaciones, puede representar un serio deterioro para los embarcadores - y consecuentemente los consignatarios - que no tengan esas características y celebren un contrato por volumen de carga, a través del cual el régimen de responsabilidad del porteador es notoriamente aligerado.

Desde nuestra perspectiva, los resquicios legales que fomentan el abuso, se encuentran desde la definición misma de los contratos por volumen. En virtud de ella, la cantidad de carga y el periodo de tiempo son indeterminados, con lo cual un pequeño volumen puede calificar para la caracterización del contrato. De igual manera, la falta de acotamiento del "periodo" hace que pueda extenderse demasiado; o bien construirse de una forma que aunque se trate de operaciones aisladas en épocas muy distintas, califique siempre para ser caracterizado dentro de la definición de contratos por volumen.

Como hemos sostenido en distintos foros - incluso en Uncitral- el texto del Convenio debe acotar efectivamente tanto los volúmenes, como los periodos, y más aún debe prever un mecanismo sencillo y eficaz a partir del cual, sin caerse en el ámbito tuitivo del derecho del consumo, sí se disponga de normas a calificar durante un proceso jurisdiccional para que, aún pese a haber contratado un contrato de volumen, una parte notoriamente no compleja pueda válidamente argumentar que el régimen de exclusión del Convenio no debe aplicarle en virtud de su evidente diferencia en capacidad negociadora frente al porteador marítimo.

No establecer límites como los antes sugeridos tendrá, desde nuestro punto de vista, dos efectos negativos para una proporción importante de operaciones de transporte marítimo: i) Propiciará abusos en los cuales el embarcador - y en consecuencia el consignatario-, pese a no calificar para ser parte de un verdadero contrato de volumen, es considerado como tal, y consecuentemente queda indefenso para evitar la exclusión del régimen de responsabilidad del porteador; y ii) Hará que sea prácticamente forzoso que los exportadores medianos y pequeños deban recurrir a un agente de logística integral, que a su vez tendrá un poder de negociación aplastante, amen de no contar con un régimen imperativo que limite su actuación frente al exportador.

Con o sin abuso, la celebración de este tipo de contratos tendrá un impacto en los aseguradores marítimos de mercancía, quienes verán minimizadas sus probabilidades de recuperación, luego de pagar al asegurado y subrogarse en sus derechos para ir en contra del porteador. Este 
efecto en el seguro de mercancías hará necesariamente que las primas de seguro para exportadores (o importadores) aumente.

\section{Las cláusulas de jurisdicción}

Como antes señalábamos, la situación en cuanto a este tipo de cláusulas es tradicionalmente grave para la mayor parte de los países - como México - y se ha agravado para otros en los cuales, previamente, las cláusulas eran declaradas nulas o bien limitadas, con lo cual, los consignatarios podían demandar en sus propias jurisdicciones. Sin embargo, a partir de resoluciones como la del Sky Reefer de 1995 por la Suprema Corte de Justicia de EUA, ahora se consideran válidas. ${ }^{136}$

Si bien algunos países — de forma ejemplar Canadá — han legislado con el fin de impedir de modo tajante la aplicación abusiva de las cláusulas de jurisdicción, impidiendo a sus judicaturas aplicar casos como el Sky Reefer, el Grupo de Trabajo ha considerado que la forma adecuada de atacar estas cláusulas abusivas es directamente en el Proyecto.

En un tema tan sensible, tener el consenso de delegaciones tan importantes como la Unión Europea - quien para este tema cuenta con competencia exclusiva - y Estados Unidos es fundamental. Sin embargo, si bien ambas delegaciones podían entender las posturas de la otra, lo cierto es que encontrar un acuerdo de auténtica uniformidad del sistema en este rubro es francamente difícil.

Como hemos ya anunciado, han existido dos posturas sobre el tema: aquellos países - la mayoría que incluye a EUA — que buscan que las cláusulas no sean ejecutables bajo ningún concepto; y aquellos - una importante minoría que incluye a la Unión Europea- que no puede aceptar que éstas no sean ejecutables al menos al interior de su región. Desde su punto de vista, lo contrario equivaldría a ir en contra de tratados comunitarios y romper su sistema jurisdiccional, difícilmente alcanzado. ${ }^{137}$

Con el apoyo de Japón y de Noruega, las delegación de EUA y de la UE han encontrado, en principio, un acuerdo que si bien no es el óptimo para la uniformidad, sí permite que el Convenio siga su curso con un me-

136 Sturley, Michael, "Overruling Sky Reefer in the International Arena: A Preliminary Assessment of Forum Selection and Arbitration Clauses in the New Uncitral Transport Law Convention", Journal of Maritime Law \& Commerce, núm. 37, enero de 2006.

137 Véase Convenio Europeo sobre Jurisdicción y Ejecución de Sentencias en Materia Civil y Comercial de 1968. 
canismo que parece cerrar la puerta a los abusos en el uso de las cláusulas comentadas.

En la propuesta conjunta, se ofrece al actor una serie de alternativas para incoar su acción, entre las que se incluye: el domicilio del porteador, el lugar de recibido; el lugar de entrega, el puerto de embarque, el puerto de desembarque; o bien, el lugar designado a través de una cláusula de selección de foro. ${ }^{138}$

Así pues, el consignatario cuenta con seis lugares alternativos para demandar, toda vez que la cláusula de selección de foro de la regla general es de carácter optativo; esto es, una cláusula de selección de foro que excluyera las demás posibilidades, habrá de tenerse por nula. En congruencia con la razón de ser de los contratos de volumen, se establece asimismo que en el caso de estos tipos contractuales, las cláusulas exclusivas de selección de foro sí son ejecutables.

Si bien se ha respetado la opción de la mayoría de las delegaciones del Grupo, otras delegaciones de importancia — como la Unión Europeano han salido perjudicadas, toda vez que permite que al depositar cada Estado miembro de la Unión Europea su respectivo instrumento de ratificación del Convenio, señale que a pesar de las alternativas del Convenio, sus tribunales ejecutarán las cláusulas exclusivas de selección de foro.

Así pues, el resultado para países — como México- que no formulen la declaración anterior al depositar su instrumento de ratificación será que los embarcadores o consignatarios serán libres de litigar válidamente en México, pues los tribunales mexicanos deberán tener por nulas las cláusulas de selección de foro que tengan naturaleza exclusiva. La única - pero sumamente importante- excepción serán estas cláusulas en los contratos de volumen. Es por ello que la regulación de los contratos de volumen es tan importante para el régimen del Convenio en general.

\section{COMENTARIOS CONCLUSIVOS}

Como hemos argumentado a lo largo de este artículo, ni las RHW ni las RHa pueden considerarse como una respuesta eficaz para las necesidades de transporte marítimo actuales. Las primeras, por ser un régimen inequitativo hacia los interesados en la carga; las segundas por no tener 
en cuenta la posición de los porteadores. La dispersión del sistema en estos dos grandes regímenes ha generado interpretaciones jurisdiccionales absolutamente contradictorias entre distintos países; con lo que lo único que efectivamente se ha logrado es la "anti-uniformidad" del derecho marítimo.

A partir de lo anterior, el esfuerzo concatenado del CMI y de Uncitral es, a todas luces, encomiable. Si bien el ejercicio no ha terminado, los resultados parciales permiten afirmar que las industrias objeto de regulación están cerca de encontrar un nuevo instrumento que les permita operar en un ámbito de certeza jurídica y equidad; pero también de sano desarrollo de negocios para todos los actores.

En este contexto de optimismo, sin embargo, nos parece preocupante que Uncitral no sea del todo asertiva en eliminar todo resquicio que posibilite continuar los esquemas de abusos por parte de ciertos porteadores marítimos y sus agentes.

En nuestra opinión, incluso los grandes aciertos del proyecto de Convenio de Uncitral - como la eliminación de la culpa náutica y la exclusión de las cláusulas exclusivas de selección de foro; o bien la adecuada regulación de transacciones electrónicas, los documentos de transporte, la transmisión de derechos y el control efectivo- se verán reducidos, de no lograr una redacción que elimine con toda claridad y eficacia el posible abuso, mediante el uso ilegítimo de los llamados contratos de volumen. 